\title{
La “cosa étnica"está de moda Performatividad, crítica y agencia en torno al discurso indoamericano en Vogue (2000-2017)
}

(1) Julimar Mora Silva

Universidad Central de Venezuela. Facultad de Ciencias Económicas y Sociales. Caracas, Venezuela. Correo electrónico: julimar.mora@gmail.com
Recibido:

21 de marzo de 2018

Aceptado:

25 de octubre de 2018

\section{Resumen}

Este artículo presenta un conjunto de reflexiones acerca de la representación asignada a lo indoamericano en las colecciones y marcas de la alta moda presentadas en las fashion weeks a partir del portal web de Vogue. Para ello, se analizaron los contenidos visuales y escritos en una doble dimensión: estética y simbólica, para evidenciar la transmisión de antiguas significaciones en "nuevas" formas de expresión. Asimismo, se discuten casos en los que estos discursos y performatividades avivaron el reclamo de grupos étnicos que criticaron discursos y apropiaciones de estilos en las performances sobre ellos referidos. El análisis de los contenidos dio cuenta de la gestación de contradicciones a todos los niveles, desde el estético asociado a la indumentaria y a la performance corporal, hasta el político, anclado a las disputas por el derecho a la propiedad e identidad asociada ciertos marcadores de etnicidad.

The "ethnic thing" is fashionable. Performativity, criticism and agency around the Indoamerican discourse in Vogue (2000-2017)

\begin{abstract}
This article presents a set of reflections about the representation assigned to the American Indian in the collections and brands of the high fashion present in the fashion weeks from the Vogue web portal. For this, the visual and written contents were analyzed in a double dimension: aesthetic and symbolic, evidencing the transmission of old in "new" forms of expression. Likewise, cases where these discourses and performances revived the claim of ethnic groups that criticized speeches and appropriations of styles in the performances about them are discussed. The analysis of the contents gave an account of the development of contradictions at all levels, from the aesthetic associated with clothing and body performance, to the political one anchored
\end{abstract}

\section{Palabras clave}

Moda; Étnico; Performatividad; Agencia; Crítica

\section{Key words}

Fashion; Ethnic; Performativity; Agency; Criticism 
to the disputes over the right to property and identity associated with certain markers of ethnicity.

\section{“Coisa étnica" está na moda. Perfomatividade, crítica e agên- cia em torno do discurso indo-americano na Vogue (2000-2017)}

\section{Resumo}

Palavras-chave

Moda; Étnica; Performatividades; Agência; Crítica
Este artigo apresenta um conjunto de reflexões sobre a representação atribuída ao índio americano nas coleções e marcas da alta moda apresentadas nas fashion weeks do portal da Vogue. Para tanto, os conteúdos visuais e escritos foram analisados em dupla dimensão: estética e simbólica, evidenciando a transmissão de antigos significados em "novas" formas de expressão. Da mesma forma, casos em que esses discursos e performatividades reavivaram a reivindicação de grupos étnicos que criticaram discursos e apropriações de estilos nas performances sobre eles são discutidos. A análise dos conteúdos deu conta do desenvolvimento de contradições em todos os níveis, desde a estética associada ao vestuário e à performance corporal, até a política ancorada nas disputas pelo direito à propriedade e identidade associados a certos marcadores de etnia.

\section{A modo de introducción}

La mujer, entonces, tiene en la mítica amerindiana mucho más lugar que en la hispánica [...] Lo femenino se emparenta, esencialmente, con la luna, el mar o las aguas, la terra mater [...] Lo masculino teogónico esta igualmente presente. Los pueblos nómades del norte o los del sur [...] adoran a dioses del cielo, dioses de cazadores y guerreros

(Dussel, 2007, pp. 15-16).

Estudiar la emergencia de lo étnico en las colecciones de moda contemporánea exige revisitar sus usos categoriales analizando su aparición en los procesos económicos, políticos y sociales que actualmente tienen lugar en el sistema-mundo moderno. Para ello, empezaremos discutiendo algunas de las dificultades que enfrenta el uso conceptual de lo étnico en los actuales circuitos de moda comercial. La etnicidad constituye un concepto polémico en torno al que se ha generado gran cantidad de discusiones cuya principal preocupación - desde "objetivistas vs. subjetivistas", hasta "materialistas vs. idealistas" - radicó en la determinación de los aspectos capaces de demarcar las fronteras entre los múltiples grupos étnicos (Bari, 2001). Los objetivistas pusieron su empeño en criterios pensados desde lo etic; es decir, desde la voz del externo investigador, y crearon a priori un inventario de marcadores tales como: hábitos, tradiciones, relatos, rituales, usos de la lengua y vestigios de cultura material, esperando con ellos precisar las propiedades responsables de la especificidad cultural de los diferentes grupos étnicos. No obstante, estas primeras interpretaciones asumieron sin mucho éxito la labor de justificar los "esencialismos culturales" en un mundo donde los cambios sociales derivados de la globalización - desplazamientos, migraciones, movilidades sociales, inserciones laborales, participación en la política nacional, etcétera - pusieron 
a prueba la integridad de los marcadores étnicos tal y como fueron conocidos a principios del siglo pasado. Así, la expansión de las fronteras del sistemamundo moderno (Wallerstein, 2006), consumada en la internacionalización de las marcas de alta moda, hizo posible que algunos de estos marcadores, especialmente los sensibles a lo estético, experimentasen una reorganización que fue resultado de nuevos usos y de apariciones en diferentes escenarios.

Por otro lado, los subjetivistas pusieron su empeño en criterios pensados desde lo emic; es decir, desde la voz del nativo investigado, y consideraron solo los marcadores identitarios que para los miembros del grupo ejerciesen cierto grado de eficacia organizativa (Barth, 1976) y contribuyesen a la cohesión del grupo a lo interno y externo de sus fronteras (entre sus miembros y en relación con otros). De esta forma, se diluyeron en el análisis los esencialismos que impidieron la comprensión de estos marcadores en un mundo donde los intercambios e hibridaciones hicieron difícil la determinación de rasgos "esenciales" para cada cultura.

Estas discusiones adquirieron importancia frente al auge de industrias culturales como la de la moda pues, marcadores tipificados como "étnicos" han sido, y continúan siendo, constantemente apropiados por firmas, marcas y empresas; en muchos casos, ajenas a sus contextos locales y regionales de producción, lo que ha promovido un continuo reordenamiento de marcadores de etnicidad considerados diferentes o, simplemente, ajenos al devenir histórico del mundo occidental. ${ }^{1}$ Por Occidente entendemos lo que Trouillot (2011) definió como Proyecto Histórico del Atlántico Norte; es decir, el conjunto de sensibilidades estéticas y estilísticas; persuasiones religiosas y filosóficas; supuestos culturales y marcos ideológicos que fueron presentados por los discursos oficiales como trazos de historia de la humanidad, sin especificar su localización geográfica (Europa Occidental, EE.UU. y Canadá), ni la singularidad de su tradición. En este marco, las sensibilidades asociadas a lo "moderno" se proyectaron como una experiencia histórica a escala mundial, al disfrazar y desconocer la validez de experiencias culturalmente diferentes.

La moda no se entenderá aquí como un ejemplo de "universalidad transhistórica" compartida por todas las culturas, en todos los tiempos, sino como "un proceso excepcional e inseparable del desarrollo del mundo moderno occidental" (Lipovetsky, 1990, p. 23). Así, interesa la representación dada a la experiencia histórica "indoamericana" en las performances promocionadas por el sistema de alta moda pues, esta última ha apropiado de marcadores de diferentes culturas (símbolos, objetos, tejidos, estampados, pinturas corporales, etcétera) y los ha traducido a un lenguaje performativo que, más que rendir tributo a la diversidad cultural, ha introyectado ideologías sobre lo que implica ser "normal" y "diferente" desde la experiencia histórica de la modernidad occidental. Esta situación conllevó a preocuparnos por la naturaleza de los discursos imputados a la alteridad indoamericana en las performances que promueven algunas marcas de alta moda, y cuestionarnos ¿de qué forma su comercialización constituye un problema para los grupos étnicos involucrados en la apropiación de marcadores simbólicos con los cuales se identificaron?

Para autores como Emanuel Amodio, los problemas de la apropiación devienen cuando se transgrede el límite del valor de un símbolo o marcador cultural, el cual está definido por "el horizonte cultural compartido por grupos locales y regionales, $[. .$.$] más allá de ellos encontrará solo su transformación y descono-$ cimiento; es decir, su negación como [símbolo o marcador] producido por una cultura específica" (1998, p. 287). A priori, este hecho no constituye un problema
1. Se alude especialmente a los usos de la lengua, las expresiones estéticas y la cultura material por considerarse marcadores susceptibles de transformarse en mercancías por parte de industrias como la moda. Sin embargo, otros marcadores, como rituales, hábitos, relatos, etcétera, también pueden ser sujeto de mercantilización. 
2. Con "potencia organizativa" hacemos referencia a la capacidad de servir como un marcador de identidad que permita a los miembros de un grupo reconocerse y organizarse en torno a un determinado elemento.

3. La performance entendida aquí como una trama de conductas y experiencias representadas que reproducen y engendran actuaciones e ideas.

4. El centro de la preocupación por la contaminación ideológica de los marcadores étnicos en el presente versa en su fetichización "comercial" o producto de su instrumentalización política a través de las ideologías nacionales oficiales.

ETNOMat es un proyecto vinculado al Departament d'Antropologia Social de la Universitat de Barcelona que tiene como objetivo investigar los vínculos entre la cultura material, la identidad y la propiedad intelectual en diferentes sociedades contemporáneas de América, África y Europa. (continúa en página 110) si se considera que la apropiación cultural no siempre deviene en conflictos políticos concretos y que, en no pocos casos, ni la moda, ni la industria que de ella deriva, se han planteado ser instancias responsables con los grupos y contextos que le sirven de inspiración. Sin embargo, comienza a significarlo en la medida que grupos étnicos concretos hacen visible su descontento.

La mundialización que hizo posible que la performatividad étnica se presentase y representase en contextos sociales vinculados con la moda otorgó a la etnicidad un nuevo problema político que abordar, uno donde la universalización del esquema "Occidente vs. Otros" dificultó el reconocimiento de particularidades culturales concretas, a la vez que encubrió el potencial de organización ${ }^{2}$ de los marcadores étnicos, ahora traducidos a performances y convertidos en mercancía. La categoría "étnico" resulta cuestionable cuando intenta aplicarse a ciertas mercancías de alta moda pues, las performances en las que se insertan no siempre tributan a la cohesión del grupo que las consume o produce. Ni las marcas, ni sus consumidores constituyen unidades étnicas en el sentido antropológico del término ya que, ni se ciñen a límites geográficos específicos, ni comparten los mismos valores, ni cuentan con miembros que se identifican y son identificados por otros como una unidad distinguible de otras del mismo género (Barth, 1976). En consecuencia, la mayoría de las performances no desempeñan funciones que comúnmente se atribuyen a la etnicidad o, al menos, no en un grueso de sus consumidores, por lo que, en no pocos casos, la etnicidad en la moda es un asunto esencialmente nominal.

Los inconvenientes asociados a la performatividad étnica en la moda y la relación que deriva de su contacto con los grupos étnicos que perciben en ella un problema exigen rediscutir su actuación en el sistema-mundo moderno. La antropología, por ejemplo, no ha dudado en aceptar que la materialidad (entiéndase lo objetual/material/corpóreo de los marcadores y símbolos "étni$\cos ^{\prime \prime}$ ) y su performatividad (entiéndase su puesta en escena en el teatro social: pasarelas, fotografías, discursos, etcétera $)^{3}$ tiene implicaciones importantes en el mantenimiento y funcionamiento de la estructura social, sea a través de la circulación económica y la satisfacción de necesidades, o a través de la objetivación y subjetivación de valores que cohesionan y diferencian a unos grupos con respecto a otros. Sin embargo, es preciso advertir que la crítica dirigida hacia la performatividad étnica promovida desde campos como la sociología o antropología - en especial, cuando se analiza en su tránsito en el mercadoha tendido a preocuparse por la "contaminación ideológica" de los símbolos y marcadores étnicos en condición de mercancía (Miller, 2009). ${ }^{4}$ Si bien es cierto, esta sola cuestión no deja entrever las fricciones que se gestan en el marco del sistema de alta moda, especialmente, los problemas que devienen de la mediación entre los apropiadores de estos marcadores (promotores de las performances: marcas de alta moda), y aquellos que le reclaman (intelectuales, activistas y miembros de grupos étnicos concretos) que avivan reacciones que transcienden el solo acto de consumo.

En ciertos casos, la performatividad étnica en la moda va más allá de una cuestión nominal y contribuye con la identificación/cohesión de grupos étnicos concretos en la medida en que sus miembros se movilizan en función de un reclamo. Los sectores demandantes varían considerablemente. Como se verá más adelante, abarcan desde diseñadores de moda comprometidos con la reivindicación de la etnodiversidad como valor agregado de sus marcas (como Oliver Rousteing [Balmain], Stella Jean y Marcelo Burlon, etcétera); pasando por movimientos y organizaciones, sociales e intelectuales (como la Organización Mundial de la Propiedad Intelectual [OMPI], ETNOMat, ${ }^{5}$ etcé- 
tera), hasta llegar a las agencias indígenas y su expresión en diferentes frentes, especialmente, en medios de comunicación (como fue el caso de las críticas impulsadas por miembros de los pueblos navajo, kuna y mixe).

La cuestión de la etnicidad en las colecciones de moda analizadas en este trabajo plantea problemas de este tipo, y es que la alta moda no puede concebirse expresión de grupos étnicos concretos, como sí, en la mayoría de los casos, del Proyecto Histórico del Atlántico Norte, el cual se ha planteado en sus discursos "the imposition of a particular interface between what happened and that which is said to have happened" (Trouillot, 2003, p. 12). ${ }^{6}$ A diferencia de contextos locales y regionales donde los símbolos y marcadores culturales se corresponden con la función que desempeñan a lo interno y externo de grupos étnicos concretos, en la alta moda, los límites de la performatividad étnica están definidos por (1) la expresión estética asociada a las mercancías; es decir, las propiedades de objeto mismo (Zborowska, 2015); (2) las fronteras comunicacionales que constriñen su circulación en determinados circuitos comerciales; y aún más importante (3) la historicidad que envuelve la performatividad de lo "diferente" en el marco del proyecto histórico que lo produce. En función de ello, la performatividad étnica en la alta moda - vista aquí a partir de las fashion weeks representadas en los discursos textuales y gráficos de Vogue - se entenderá como una totalidad compleja que será analizada en función de los símbolos y marcadores culturales en él manifiestos. Estos símbolos se unifican/ combinan en tramas performativas más o menos homogéneas que representan una misma cosa: la "cosa étnica" que no puede ser entendida, ni problematizada si se piensa aislada de la historicidad que configuró su posición en el imaginario moderno occidental. El presente trabajo iniciará por reconocer el conjunto de valores estéticos y significativos asignados a lo indoamericano, para luego conectarlos con los discursos sobre ello referidos en Vogue. Con esto se buscará analizar su continuidad y transformación en el tiempo, así como los problemas que devinieron de su promoción. Y, aunque, el reclamo no constituyó la única posibilidad de agencia de cara a la apropiación, las siguientes líneas centrarán su atención en los problemas que derivaron de la masificación de estas representaciones, esperando contribuir al conocimiento de los espacios donde se expresa la crítica hacia la apropiación cultural de marcadores y símbolos de etnicidad.

\section{Método, datos y análisis}

El análisis del discurso constituyó la principal herramienta para el análisis de las fuentes tomadas en el presente trabajo. Se consideraron fuentes los textos e imágenes referidos a la promoción de las colecciones de moda en las fashion weeks realizadas entre los años 2000 y 2017, y se extrajeron los datos del portal web de Vogue. Como criterio de búsqueda se utilizaron etiquetas clave como: ethnic (etnia, étnico), tribal, tribes (tribus, tribales), indigenous (indio, indígena, nativo) y exotic (exotismo, exótico), las cuales permitieron identificar las colecciones de moda que hacían o no referencia a la idea de lo indoamericano, entendiendo este último término no como condición real y concreta de una identidad autoasignada por los grupos sociales insertos en ella, sino más bien como la "definición que dieron sus [supuestos] 'descubridores' [potencias europeas como: España, Inglaterra, Francia y Holanda a partir del contacto]" (Frey, 1996, p. 53). En las siguientes líneas, se presenta un listado de las colecciones de moda a partir de las cuales se tomaron los textos e imágenes sujetos a análisis (véase el cuadro 1):
6. [Traducción] “la imposición de una interfaz particular entre lo que sucedió y lo que se dice que ha sucedido". 
Cuadro 1. Colecciones de análisis

\begin{tabular}{|l|l|l|}
\hline Firma, marca, diseñador & \multicolumn{1}{|c|}{ Colección } & \multicolumn{1}{c|}{ Año (tipo) } \\
\hline Stella Jean & Fall-Winter & 2016-2017 (Womenswear) \\
\hline Junya Watanabe & Spring & 2016 (Menswear) \\
\hline Marcelo Burlon County of Milan & Fall & 2015 (Menswear) \\
\hline Dimitri & $\begin{array}{l}\text { Berlin Fall } \\
\text { Berlin Spring }\end{array}$ & $\begin{array}{l}2015 \text { (Womenswear) } \\
2016 \text { (Womenswear) }\end{array}$ \\
\hline Valentino & $\begin{array}{l}\text { Spring Couture } \\
\text { Ready-to-Wear }\end{array}$ & $\begin{array}{l}2014 \text { (Womenswear) } \\
2015 \text { (Womenswear) }\end{array}$ \\
\hline Maison Margiela & Spring & 2014 (Womenswear) \\
\hline Balmain & Pre-Fall & 2014 (Womenswear) \\
\hline Chanel & Métiers d'Arts & 2013 (Womenswear) \\
\hline Diane Von Furstenberg & Spring Ready-to-Wear & 2010 (Womenswear) \\
\hline Gucci & Spring-Summer & 2010 (Womenswear) \\
\hline Louis Vuitton & Spring-Summer & 2010 (Womenswear) \\
\hline Marc by Marc Jacobs & Spring Ready-to-Wear & 2010 (Womenswear) \\
\hline Dries Van Noten & Spring Ready-to-Wear & 2010 (Womenswear) \\
\hline Sebastian Pons & Spring Ready-to-Wear & 2004 (Womenswear) \\
\hline Emanuel Ungaro & Fall & 2002 (Womenswear) \\
\hline $\begin{array}{l}\text { Museo Peabody Essex y Museo } \\
\text { Nacional del Indio Americano }\end{array}$ & Native Fashion Now & $\begin{array}{l}\text { Diseñadores, colecciones y años } \\
\text { diversos }\end{array}$ \\
\hline
\end{tabular}

Fuente: Portal web de la revista Vogue.

Es necesario señalar que muchas de estas colecciones refirieron lo étnico de forma más o menos genérica; es decir, reseñaron estilos y estéticas que desbordaron por mucho el imaginario acerca de lo indoamericano. Se tomaron la mayoría de los contenidos que refirieron etiquetas geográficas, étnicas e históricas que aludiesen imaginarios y contextos asociados al mundo americano. Para el análisis de los contenidos se emplearon técnicas de la semántica estructural (Coseriu, 1977), y se determinaron los semas (elementos constitutivos que definen la función binaria de las unidades significantes) y campos semánticos (redes léxicas de significación) que dieron sentido a los discursos sobre el exotismo indoamericano publicados por Vogue durante el período planteado.

Para ello, se procedió a:

1. Ubicar los discursos escritos relacionados con las etiquetas descritas previamente en el portal web de Vogue.

2. Aislar los semas que intuitivamente -es decir, a primera impresión- parecieron tener relación con el campo semántico de interés; en este caso, el campo ligado a la idea de exotismo.

3. Agrupar los semas aislados de acuerdo con nodos que les dieran sentido; en este caso, de acuerdo con subcampos tales como espacio, tiempo, forma y función.

4. Examinar la asociación de los discursos escritos y visuales con otros datos y fuentes consideradas.

El análisis de los datos tanto escritos, como visuales pasó por analizar los símbolos y significados que fueron aplicados tanto al objeto étnico, como al cuerpo portador, centrando la atención en lo que Leticia Mayer Celis denominó 
la dimensión performativa del símbolo; es decir, "cómo este se usa, qué actitudes despliega, cómo se orienta y, en general, qué espacio ocupa respecto a otros símbolos" (2016, p. 47), y así comprender la reacción avivada por los grupos étnicos que hicieron patente su reclamo. Las críticas que se exaltan al final del trabajo se tomaron también del portal web de Vogue, y fueron considerados además los contenidos noticiosos relacionados con los escándalos y denuncias dirigidas hacia diseñadores y marcas de alta moda entre los años 2000 y 2017. Algunos de estos, como fue el caso de los Navajo y la propuesta "Métiers d'Arts", de Chanel, tuvieron que ver directamente con las colecciones de moda analizadas. Otros ejemplos - como la apropiación de la "mola" de los mayas y kunas, y el "huipil" de los mixe- son exaltados como muestra de las ambivalencias que promueve Vogue al hacerse portador de críticas hacia apropiaciones que su plataforma promociona.

\section{Vogue, fashion weeks y ethnic chic. Artefactos del proyecto histórico occidental}

Entender la relación de Vogue y eventos como las fashion weeks en el marco del proyecto histórico que los produce exige un previo develamiento de su dimensión en la administración de discursos e imaginarios a escala mundial. Para ello, es preciso destacar la distinción realizada por Elise Van der Laan y Giselinde Kuipers (2016) quienes definen la alta moda como un proyecto principalmente editorial, un poco diferente a la baja moda en la medida que esta última constituye un proyecto de tipo comercial.7 Esta distinción es importante pues, atribuye a la alta moda una gran responsabilidad en la generación de contenidos simbólicos y estéticos que, en función de su prestigio y asociación con la alta cultura (Bourdieu, 1993), en muchos casos, se toman como referencia por las estructuras prêt-à-porter (estructuras comerciales centradas en el consumo masivo) las cuales, se sirven de la imitación en provecho de los mercados que devienen del éxito de las tendencias posicionadas por el sistema de alta moda.

Las fashion weeks constituyen eventos de moda dedicados a la promoción de prendas de vestir exclusivas que se realizan periódicamente (con colecciones en otoño, invierno, primavera y verano) en tradicionales ciudades como Nueva York, Londres, Milán y París. Nacieron en Nueva York (1943) bajo un proyecto de internacionalización de las mercancías norteamericanas y europeas en el marco de la expansión comercial que tuvo lugar en el período de entreguerras, y lograron extenderse y fortalecerse en la segunda mitad del siglo XX con la progresiva comercialización impulsada por el proceso de tercerización de la economía (la población económicamente activa se concentró en la distribución de bienes y servicios); la creación de instituciones propicias a la expansión comercial (asociaciones, cámaras y gremios comerciales); el avance tecnológico; el apogeo de la comunicación en masa y la mejora en el sistema de transporte (Mora, 2018). La primera fashion week se realizó en Nueva York con el fin de captar la atención de las tradicionales pasarelas realizadas en Francia. No obstante,

mientras en Paris los desfiles de moda proliferaban en salones a puerta cerrada pensando en una elite exclusiva, en EE.UU. los grandes almacenes organizaban las presentaciones [...contexto ante el que] la publicista Eleanor Lamber organizó las Press Weeks con el objetivo de que periodistas y editores de moda incluyesen diseñadores americanos en sus reportajes [... Así,] las Press Weeks fueron un éxito y a través de revistas como Vogue y Harpers Bazaar se impulsó [a gran escala] la moda y diseñadores americanos. (Perez-Serrabona, s.f., pp. 21-26)
7. Las distinciones entre alta y baja moda de acuerdo con Van der Laan y Kuipers (2016) no niegan que la alta moda contenga una dimensión comercial y viceversa. sin embargo, es claro que el prestigio asignado a las marcas de la alta moda le confieren un carácter editorial superior al que se percibe en la baja moda. 
8. Vogue ha sido la primera publicación de moda estadounidense que logró penetrar y conquistar Europa. Hoy está considerada la publicación de moda más influyente del mundo y se edita en más de veinte países.

9. La migración del consumo de publicaciones físicas a virtuales; es decir, disponibles en la web, ha dificultado la obtención de datos precisos respecto de la condición socioeconómica, incluso étnica, de los consumidores de Vogue en los contextos mencionados. No se hallaron estudios que mostraran datos de esta naturaleza.
La necesidad de posicionar las creaciones de moda de los diseñadores norteamericanos sujetó la relación de Vogue a las fashion weeks. El prestigio de ambas plataformas se gestó de forma simbiótica. ${ }^{8}$ En principio, las fashion weeks fueron creadas con la intención de posar la atención sobre los diseñadores emergentes de un determinado país o región y así promover las industrias locales y nacionales, a la vez de aumentar sus posibilidades de exportación hacia mercados internacionales. Sin embargo, con el transcurrir de los años, las fashion weeks fueron expandiéndose a contextos externos a EE.UU. y Europa Occidental, y llegan a posicionarse en el presente en contextos como Australia, Nueva Zelanda, África, Canadá, China, Croacia, India, Indonesia, Malasia, Rusia y México. Estos eventos permitieron a los comerciantes minoristas organizar sus compras e incorporar el trabajo de diseñadores emergentes en su comercialización al por menor pues, en ellos tienen lugar presentaciones de las marcas con mayor prestigio. El éxito de las fashion weeks ha estado determinado por el número de modelos de renombre que participan en él (modelos de pasarela femeninas como Naomi Campbell, Cindy Crawford, Kate Moss, Amber Valletta, Heidi Klum, Karlie Kloss, Cara Delevingne, Kendall Jenner, Gigi Hadid, Bella Hadid, etcétera; y masculinos como: Sean O'Pry, Jon Kortajarena, Brad Kroenig, Tyson Beckford, etcétera); así como por su asociación con diseñadores y marcas prestigiosas (Dior, Chanel, Céline, Hérmes, Diane Von Furstenberg, Gucci, Calvin Klein, Marcelo Burlon County of Milan, Dimitri, Michael Kors, Tommy Hilfiger, Ralph Lauren, Burberry, Stella McCartney, Versace, D\&G, Prada, Valentino, etcétera); compradores corporativos (Farfetch, Saks, Neiman Marcus, Bloomingdale's, Nordstrom, Barneys New York, Macy's, etcétera); y no menos importante, por la cobertura mediática que generan (English, 2013), todos estos fenómenos que potencian el alcance mundial de sus contenidos editoriales.

Investigaciones como las realizadas por Brian Moeran (2004), John Hartley (2009), Julia Twigg (2010), Chloe Marie Songer (2014), Yan Yan y Kim Bissell (2014), Patricia Soley-Beltran (2015), Drurdja Bartlett (2015) y otros, alertan sobre tres acontecimientos importantes. El primero de ellos tiene que ver con la expansión del alcance mediático de Vogue, presente no solo en los contextos baluartes de la moda (EE.UU., Reino Unido, Italia y Francia), sino también en mercados emergentes como India, Japón, China, Rusia y ciertos países de África y América Latina. El segundo aspecto guarda relación con el capital que circula y acumulan las multinacionales, marcas corporativas y firmas personales al servir de promotores, avales y patrocinantes de este tipo de eventos y publicaciones. El tercero evidencia el carácter centrífugo de las prácticas de consumo de mujeres y hombres de todo el mundo, en relación con los contenidos promovidos desde las plataformas internacionales de Vogue. ${ }^{9}$

Tener conciencia de que publicaciones como Vogue y eventos como las fashion weeks constituyen solo una parte de las estructuras comerciales que aseguran el consumo de contenidos editoriales asociados a la moda conduce a admitir cierta complejidad para rastrear su influencia en esferas que transcienden los límites de su institucionalidad; es decir, más allá de las cifras de publicaciones vendidas, visitas al su portal web o cantidad de prendas comercializadas por las firmas partícipes en estos eventos. Lo que sí es claro es que proyectos editoriales como Vogue y publicaciones afines como Elle, Cosmopolitan, Glamour y otros, tienen actualmente un alcance a nivel mundial, situación que contribuye a que su influencia se expanda más allá de los circuitos de alta moda. De manera inmediata, sus contenidos repercuten en marcas low cost de talla mundial ancladas al estándar del lujo europeo (símbolos de modernidad y distinción comercializados por plataformas comerciales más accesibles); por ejemplo, 
Zara, Stradivarius, Pull \& Bear, Massimo Dutti, Bershka, Uterqüe, Oshyo, Mango, H\&M, etcétera, ${ }^{10}$ y de manera menos inmediata, en sectores comerciales periféricos que no se desprenden de los grandes capitales mundiales (Bur, 2013).

Esta cadena de relaciones hizo posible que la "cosa étnica" se consumiese en lo ideal - en los contenidos estudiados en este trabajo- y en lo concreto - en las mercancías que circulan en la alta moda y estructuras comerciales pequeñas sujetas a su influencia (franquicias, tiendas físicas y virtuales, etcétera) - . Estudios recientes hacen notar que el tema étnico ha sido constante en los contenidos promovidos por la moda en los últimos años (véanse los estudios de Jean Borgatti, 2015; Christine Delhaye y Rhoda Woets, 2015; Timothy Lindgren, 2015 y otros). ${ }^{11} \mathrm{Al}$ respecto, Emma Tarlo (2000) reconoce las performatividades étnicas en la moda bajo el eslogan de "ethnic chic". Esta etiqueta constituye un significante frecuente para referir cualquier comportamiento y artefacto que parezca exótico, primitivo, o simplemente, no occidental ante la mirada de quien lo consume y produce. Su tendencia comenzó a popularizarse durante el período hippie de los años setenta, cuando ciudadanos norteamericanos y europeos se asumieron "étnicos" por llevar puesta ropa que creyeron provenía de otras etnicidades, pueblos o regiones. En EE.UU., esta tendencia comenzó a solaparse con el Native American Style el cual, centró su atención en el ropaje utilizado por los indígenas norteamericanos. Posteriormente, la negativa al movimiento hippie por parte del gobierno y un sector importante de la sociedad estadounidense polarizada por los acontecimientos relacionados con la guerra de Vietnam, acompañada de un creciente dinamismo en el flujo de las tendencias de moda y el surgimiento de estéticas alternativas diferentes a la étnica, ${ }^{12}$ conllevaron a su intermitencia en el resto del siglo y emergieron con contundencia entre los años 2010 y 2017.

El ethnic chic puso en marcha una comercialización en masa de productos tales como ropa, textiles y accesorios los cuales, desde lo estético, impulsaron una singular forma de entender la etnicidad, una etnicidad ecléctica, objetivada y carente de mayores rasgos de particularización cultural, sin especificidad de los contextos, grupos, usos y significados de los marcadores de etnicidad que pretende promover o comerciar. Pese a que esta tendencia agrupó todo tipo de expresiones estéticas, en ella pueden distinguirse estereotipos muy generales que intentaron imitar los grandes hitos de alteridad occidental, entre los que destacan las representaciones de estilos como el chino, el hindú, el nórdico, el surasiático, el árabe, el indoafricano y el indoamericano, ${ }^{13}$ lo cual, como señala Lindgren (2015), ha representado un problema para las iniciativas locales en las que se han querido posicionar propuestas alternativas a la lectura eurocéntrica del mundo.

En los últimos años, el ethnic chic avivó en las colecciones de marcas y diseñadores de alta moda, entre los que destacan nombres como: Stella Jean, Junya Watanabe, Marcelo Burlon County of Milan, Dimitri, Maison Margiela, Valentino, Balmain, Diane Von Furstenberg, Gucci, Louis Vuitton, Marc by Marc Jacobs, Dries Van Noten, Sebastian Pons, Emanuel Ungaro, Chanel y otros. Las revistas y pasarelas en todo el mundo sirvieron de escenario a todo tipo de experimentaciones estéticas, en especial, fusiones que combinaron los supuestos objetos étnicos con estilos atribuidos a otros tipos de imaginarios, entre las que predomina el encuentro de estilos modernos y aquellos que pretendieron imitar conceptos tildados de "primitivos" y "tribales" (véase la Figura 1).
10. En un estudio de mi autoría dedicado a analizar el éxito de estos grupos comerciales en países latinoamericanos y caribeños, muestro cómo el "fin de las ideologías"... (continúa en página 110)

11. Jean Borgatti (2015) narra cómo textiles y estéticas Yoruba (africanas) han sido explotadas en el marco de la alta moda europea a través de los diseños y mercancías de marcas como la de Ade Bakare's. (continúa en página 111)

12. Recuérdense las resignificaciones y apropiaciones de los estilos rastafari, punk, beatnik, lowbrow, pop, gótico, boheme y otros, los cuales tomaron la inspiración de los frentes y resistencias propios de los años sesenta, setenta y ochenta.

13. Las burkas (hijab) encabezan los accesorios que estereotipan la moda árabe en las pasarelas. Plumas, ruanas (ponchos) y máscaras constituyen algunos de los objetos que comúnmente representan las culturas amerindianas. (continúa en página 111) 


\begin{abstract}
FIGURA 1. Moda étnica en las marcas de alta moda Fuente: La imagen 1 forma parte de la colección de Marcelo Burlon County of Milan para el "Fall 2015 Menswear". Disponible en el artículo de Angelo Flaccavento (2015). La imagen 2 forma parte de la colección de Valentino para el "Spring Couture 2014". Disponible en el artículo de Nicole Phelps (2014). La imagen 3 forma parte de la colección "Métiers d'Arts" de Chanel. Disponible en el artículo de Mario Ximénes (2013). La imagen 4 forma parte de la colección de Emanuel Ungaro para el "Fall 2002 Couture”. Disponible en el artículo de Sarah Mower (2002).
\end{abstract}

14. Stella Jean ha colaborado con la iniciativa de moda ética impulsada por el Centro de Comercio Internacional. (continúa en página 111)

15. Marcelo Burlon (diseñador argentino) se define como un "vagabundo cultural". Su lema es pensar su mundo local actuando globalmente; concibe su marca como una licuadora multicultural de moda basándose en elementos iconográficos de diferentes culturas y creó su propia simbología y celebración de la diversidad. Visítese el portal web:

https://www.marceloburlon.eu/

16. En reiteradas ocasiones Olivier Rousteing, diseñador de Balmain, ha reiterado la necesidad de revolucionar la representación multicultural en la alta moda incorporando la diversidad cultural no solo en los temas de las colecciones, sino también en la participación de los modelos (Bauck, 2016).

17. Blogs de relevancia internacional como: Amlul (https:// www.amlul.com), The Sartorialist (http://www.thesartorialist.com), Song of Style (www.songofstyle. com), We Wore What (http:// weworewhat.com/) y otros, han destacado contenido que promocionan dicha tendencia.

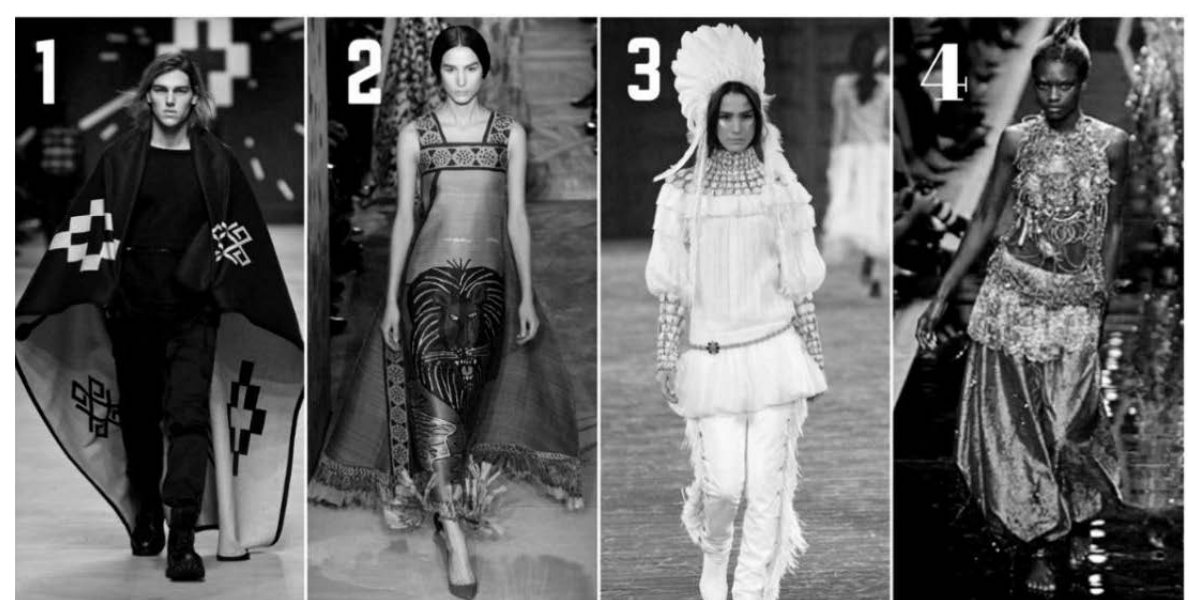

Diseñadores como Stella Jean y Marcelo Burlon, próximos al tema de la interculturalidad caribeña y latinoamericana, dieron cuenta de sus compromisos con la diversidad cultural por medio de los discursos editoriales de sus marcas. De ascendencia haitiana-italiana, ${ }^{14}$ Stella Jean planteó la coexistencia pacífica entre tres mundos aparentemente contrapuestos: el sur de Europa, el Caribe y África, y promovió un modelo de negocio en el que el trabajo de los artesanos y productores locales fuese visibilizado a través de producciones más abiertas e inclusivas en el sistema de alta moda (véase el artículo "Stella Jean: difundir la diversidad cultural y el respeto a la dignidad humana"). Marcelo Burlon ${ }^{15}$ atribuye su inspiración a "los símbolos de los mapuches y tehuelches de la Patagonia" (Rodríguez, 2014). Mientras diseñadores como el japonés Junya Watanabe, el bielorruso Dmitry Sholokhov (Dimitri) y el francés Olivier Rousteing (Balmain) también dieron cuenta de una posición crítica a la representación dada a la multiculturalidad en el escenario de alta moda. En este sentido, se destaca la promoción que en 2015 dirigió Junya Watanabe a las estéticas africanas inspiradas en el pueblo karamojong de Uganda, organizada en el Museo de Historia de la Inmigración en París el cual, según Mower, constituyó una sátira al realizarse, nada más y nada menos, que en uno de los templos "de Art Deco construidos para celebrar los beneficios culturales del colonialismo francés cuando se pensaba que ese tipo de cosas acumulaban para la gloria de la república" $(2015, \S 1)$. También destacan los modelos "étnicamente diversos" presentes en las exposiciones realizadas por Balmain (Marriott, 2015). ${ }^{16}$ En paralelo, marcas europeas más tradicionales, como es el caso de Gucci, Louis Vuitton, Chanel y otras de las mencionadas anteriormente, hicieron gala de la diversidad cultural en sus diseños. No obstante, con menos sentido de denuncia y énfasis de la crítica en sus discursos oficiales.

Al trascender las diferencias en los discursos editoriales de cada firma, marca y diseñador, la narrativa de Vogue revivió la sensación de prestigio atribuido a las prendas de alta moda, y así, dio paso a que otros blogs y portales de opinión auspiciasen el consumo de mercancías de moda asociadas con el tema étnico. ${ }^{17}$ La performatividad étnica en Vogue actuó como un criterio de doble distinción. Por un lado, una distinción cultural, valiéndose del influjo de la alta moda para posicionar contenidos políticos de vieja data; y por otro lado, una distinción significante, que posicionó lo étnico como antagonismo semántico respecto de Occidente. Así, las estéticas referidas a tejidos amerindianos y africanos, acompañadas de un uso constante de plumas, iconografía animal, colores vistosos, conchas, máscaras y accesorios "exóticos" contrastaron, en forma y función, con prendas como blazers, gorras, chaquetas, vestidos cortos 
y pantalones ceñidos al cuerpo, expresiones estéticas asociadas al imaginario moderno (véase la Figura 4).

\section{Juicios de larga data. Lo étnico como valor estético en el pro- yecto histórico occidental}

Las representaciones dadas al mundo indígena en las obras de Bernardino de Sahagún ([1569] 1938), Theodor De Bry (2003), en su serie de pequeños y grandes viajes publicada entre 1590 y 1634, Joseph Gumilla ([1741] 1944), Filippo Salvatore Gilij ([1780-1784] 1995) y otros artistas, viajeros y cronistas del período colonial, posicionaron la idea de que las sociedades amerindianas yacían de rito en rito, sin cotidianidad y una vida de todos los días (Amodio, 1997), lo que justificó una oposición entre el carácter sobrio de la cultura occidental y el carácter exótico de todo lo ajeno a su marco cultural. La asociación estética de la belleza al placer y de lo extraño a la aversión, acompañada de una instrumentalización de los estándares de perfección, simetría y armonía estimados por EE.UU. y Europa occidental parcializaron la experimentación del agrado hacia lo que su proyecto histórico consintió socialmente; y del miedo hacia lo que, otras veces, inhibió por considerar diferente (Guzmán Marín, 2000; Bartra, 2011). Lo étnico se concibió como un móvil de experiencias tales como el recelo y el desconcierto en los relatos en los que sus símbolos fueron asociados al peligro y lo profano (flechas envenenadas, maracas, máscaras, etcétera), y de placer en aquellos donde sus símbolos se asociaron a la erótica (joyas, perlas, pedrerías, plumas y otros objetos coligados a lo bello) (véase la Figura 2).

El sentido sucinto en los discursos gráficos y textuales de Vogue bifurcó la performatividad étnica en dos campos relacionados dialécticamente, uno primero emisor de armonía, docilidad y contemplación; frente a un segundo transmisor de disonancia, ferocidad y provocación. De esta forma, se activaron dos conjuntos de sensaciones aparentemente antagónicas. Por un lado, unas que - usando la metáfora planteada por Herbert Marcuse (1983) - devinieron del "Eros", como fue el caso del agrado dirigido a la manifestación de un exotismo armónico, representado en una alteridad erotizada (asociada a arquetipos de feminidad occidental) y, por otro lado, otras que devinieron del "Tánatos", como fue el caso del desconcierto dirigido hacia manifestaciones de un exotismo discordante, representado en alteridades cuyos rasgos fueron

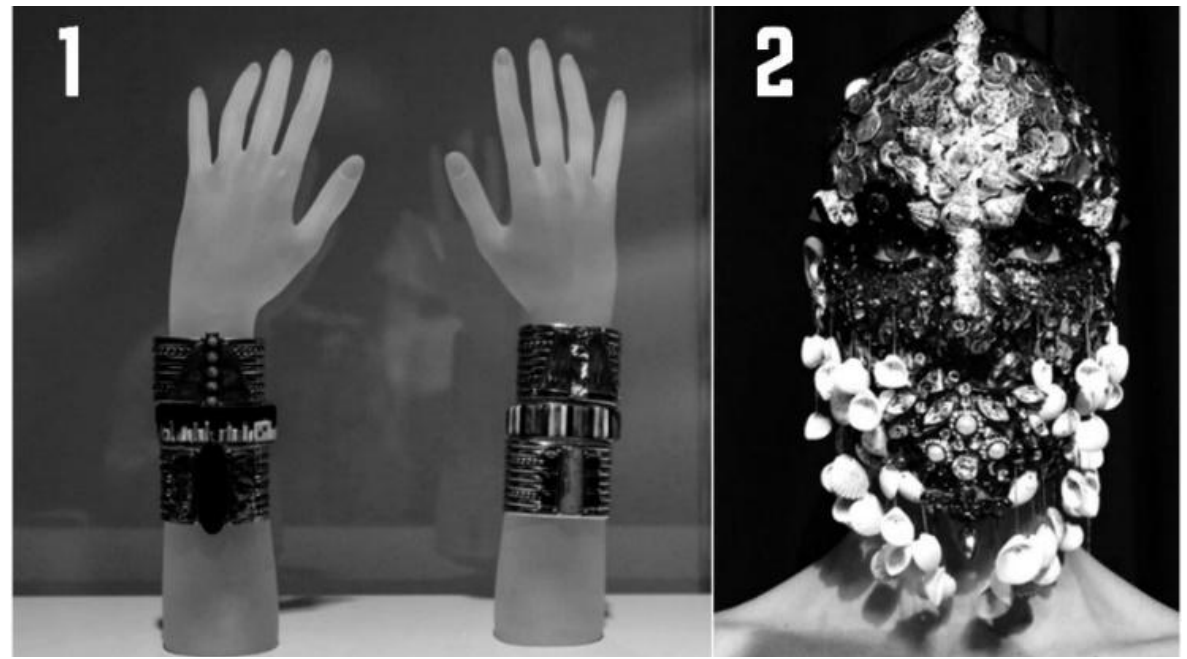

FIGURA 2. Eros vs. Tánatos Fuente: Esta imagen forma parte de la colección del "Native Fashion Now" organizada por el Museo Peabody Essex. En ella se evoca, mediante la orfebrería y la pedrería preciosa, el imaginario de una América femenina. Imagen descargada de Internet. Disponible en el artículo de Ruth La Perla (2017). La imagen 2 forma parte del espectáculo Givenchy "Fall 2015". En ella se evoca el imaginario de un tipo de salvaje oscuro, misterioso e incognito. Disponible en el artículo de Mckenzie Wagoner (2015). 
18. La primera imagen de la figura 2 constituye una metáfora de la docilidad americana ante las políticas extractivas de Occidente: plata, pedrería y demás metales preciosos dispuestos al consumo de las elites de la sociedad criolla y europea en las Américas. Entretanto, la segunda imagen de la misma figura muestra el lado bélico del mundo indígena expreso en una máscara de guerra, analogía del Tánatos.

19. Como ejemplo de estas políticas destacan: (1) la institucionalización económica capitalista de los modos de producción y circulación de marcadores culturales por parte de los grupos étnicos. Algunos de ellos, como es el caso del pueblo navajo, se han visto obligados a registrar marcas y empresas para proteger y patentar el derecho de propiedad de sus marcadores culturales. Por otro lado, (2) destacan las adaptaciones de estilo que muchos de estos grupos han tenido que adoptar para hacer rentable su producción, especialmente en contextos donde el turismo es una actividad económica central.

20. [Traducción] “mujer sexy, adulta joven que traiciona a su pueblo por un amante".

FIGURA 3. Tánatos y Centauros vs. Eros y Lápitas Fuente: Véase el exotismo y la ferocidad que se atribuye a la imagen 1. Disponible en el artículo de Shruti Thacker (2012). Préstese atención a la sobriedad y docilidad que se atribuye a la imagen 2. En ella se conjugan piezas como un blusón "cowboy" y una falda inspirada en los indígenas norteamericanos. La fusión estética entre los objetos constituye un reflejo de la simbología intrínseca a la performance de la imagen. Disponible en el artículo escrito por Pedro

Zozaya (2010). En el segundo caso se evidencia una metáfora del proceso civilizatorio: la nativa cede al uso del objeto colonizador, y gana así la apacibilidad y la mesura que la distingue de la primera. distorsionados (deformados, ocultos, exagerados, etcétera). ${ }^{18}$ Pese a diferentes, ambas tendencias reforzaron un único valor significativo: la idea de exotismo.

\section{Performances que dicen cosas. Lo étnico como valor signifi- cativo y comercial en el proyecto histórico occidental y en la alta moda}

La representación de lo étnico en los contenidos de Vogue revivió viejos conceptos en relación con la extravagancia de todo aquello situado a los límites del horizonte cultural occidental, conceptos que, al igual que los valores estéticos y sus consecuentes experiencias, precedieron la ejecución de políticas civilizatorias concretas. ${ }^{19}$ Lo étnico fue presentado como un significante estanco en el tiempo, anclado a viejos estereotipos en torno al buen y mal salvaje, así como a antiguas representaciones sobre la feminidad y masculinidad indoamericana. En el primer caso, abunda lo que Annelies Moors (2014, p. 3) denominó la "pocahontización" de la figura étnica; es decir, la reproducción de relatos en los que se promueve la simbolización de una "girl as a sexy young adult female who betrays her people for a lover", metáfora que se expresó tanto en la docilidad de su puesta en escena, como en la combinación de sus prendas (por ejemplo: un blusón blanco, masculino y colonial, junto con una falda con flecos tipo Pocahontas).$^{20}$ En el segundo caso, abundaron las expresiones referidas a una actitud bélica representada en modelos indómitos a los que se imputaron atributos como el anonimato y la ferocidad en su expresión (véase la Figura 3).

Ambos sentidos no solo se hallaron en los contenidos propios de la imagen, también estuvieron presentes en las narrativas textuales. De esta forma, se advirtieron correspondencias que reafirmaron el significado asociado a la estética performativa. A continuación, se presentan algunos ejemplos de los campos semánticos ligados a la idea de exotismo en los discursos de Vogue (véase el Cuadro 2).
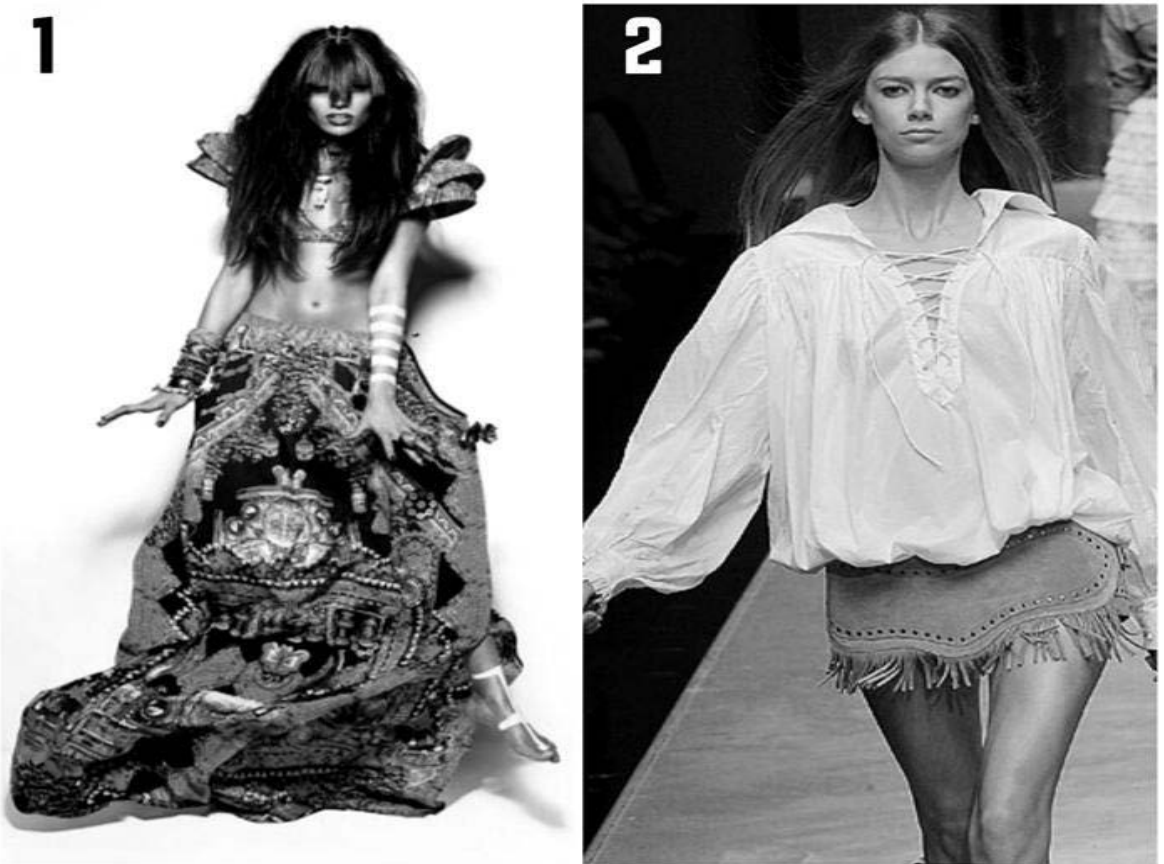
Cuadro 2. Sentidos asociados a lo "étnico" en la promoción de Vogue

\begin{tabular}{|c|c|c|}
\hline Discurso & Semas/ Campo semántico & Sentido \\
\hline \multirow{2}{*}{$\begin{array}{l}\text { Reinventando el estilo étnico } \\
\text { Las grandes firmas caen rendidas de nuevo ante la explosión } \\
\text { de color y motivos de líneas orgánicas y las adaptan a sus } \\
\text { señas de identidad: es el caso de Etro y su reinvención del folk, } \\
\text { de Valentino y su inmersión en las culturas indígenas [...] Lo } \\
\text { mejor de una tendencia tan ecléctica y dilatada son las infinitas } \\
\text { posibilidades a la hora de adaptarlo al día a día y al estilo propio } \\
\text { [...] todos pueden combinarse entre sí sin mesura creando } \\
\text { mezclas que funcionan por exceso y looks que parecen sacados } \\
\text { del corazón de la jungla (González 2014). }\end{array}$} & $\begin{array}{l}\text { Color, orgánico, folk, indígena y } \\
\text { jungla }\end{array}$ & $\begin{array}{l}\text { Exotismo estética, } \\
\text { geográfica y cultural }\end{array}$ \\
\hline & $\begin{array}{l}\text { Ecléctico, combinación y } \\
\text { adaptación }\end{array}$ & $\begin{array}{l}\text { Encubrimiento mediante } \\
\text { el cruce y mestizaje }\end{array}$ \\
\hline $\begin{array}{l}\text { Indio Navajo } \\
\text { Regresamos a los orígenes [...] este verano encontramos } \\
\text { otra apetecible tendencia de lo más orgánica que sigue las } \\
\text { mismas pautas. Se trata de unas prendas que nos invitan a } \\
\text { fundirnos directamente con la tierra y la naturaleza, abogando } \\
\text { por estampados rupestres que evocan la esencia de los } \\
\text { primeros indios apaches norteamericanos (Zozaya, 2010). }\end{array}$ & $\begin{array}{l}\text { Orígenes, orgánico, naturaleza, } \\
\text { rupestre e indígena }\end{array}$ & $\begin{array}{l}\text { Representación del alter } \\
\text { como un asunto pasado }\end{array}$ \\
\hline \multirow{2}{*}{$\begin{array}{l}\text { Balmain se pasa al lado salvaje } \\
\text { Estas mujeres son las Amazonas del futuro. Y el color de piel } \\
\text { no importa, lo que importa es la diversidad [...] Ellas son } \\
\text { depredadoras, no tienen miedo a nada, y creo que ahora más } \\
\text { que nunca tenemos que romper moldes, y no solo en la moda, } \\
\text { sino también políticamente. Palabras de Olivier Rousteing } \\
\text { (Menkes, 2017). }\end{array}$} & Amazonas, depredación y miedo & $\begin{array}{l}\text { Reproducción mítica del } \\
\text { otro como un salvaje }\end{array}$ \\
\hline & Diversidad & $\begin{array}{l}\text { Lo diverso como } \\
\text { transgresión }\end{array}$ \\
\hline \multirow{2}{*}{$\begin{array}{l}\text { Con una especie de broches con forma de labios, las modelos } \\
\text { parecían tótems tribales que, según describió el diseñador, } \\
\text { atravesaban paisajes asombrosos como el Amazonas o el } \\
\text { Serengueti (Menkes, 2017). }\end{array}$} & Tótem & $\begin{array}{l}\text { El objeto étnico como } \\
\text { fetiche, culto a la erótica } \\
\text { femenina }\end{array}$ \\
\hline & Amazonas y Serengueti & $\begin{array}{l}\text { Exotismo geográfico y } \\
\text { cultural }\end{array}$ \\
\hline $\begin{array}{l}\text { Retrato vs. Máscara } \\
\text { Stella Jean creció con los clichés de la imagen europea, por } \\
\text { lo que su destreza consiste en tomar los osados estampados } \\
\text { africanos y adaptarlos a los looks occidentales. Abrigos } \\
\text { llamativos, chaquetas de buen corte y faldas que parecían } \\
\text { sacadas del armario de una dama colonial. Pero estas prendas } \\
\text { de sastrería, como las prendas de punto, lucían muy estilosas } \\
\text { gracias a los fragmentos estampados de motivos africanos } \\
\text { (Menkes, 2017). }\end{array}$ & Adaptación, Occidente y colonial & $\begin{array}{l}\text { Proceso de civilización } \\
\text { por medio del cruce y el } \\
\text { mestizaje }\end{array}$ \\
\hline $\begin{array}{l}\text { Highly Preppy. Otoño-Invierno 2016-2017 } \\
\text { "Tropas \& Tribes" (tropas y tribus) resume en dos palabras una } \\
\text { colección que toma como referencia el choque estético de los } \\
\text { primeros conquistadores del Nuevo Mundo (De Asís, 2017). }\end{array}$ & Choque y estética & $\begin{array}{l}\text { El choque estético como } \\
\text { analogía de la fricción } \\
\text { interétnica }\end{array}$ \\
\hline
\end{tabular}

Los semas se superpusieron y complementaron en relación con signos comunes que evidenciaron la existencia de políticas de sentido consistentes y articuladas entre sí. La consecuente alusión a explosiones de color, estampados y líneas orgánicas dirigió la atención a un exotismo estético que se complementó con la alusión a espacios e identidades asociadas a lo indígena. De esta forma, se evidenciaron los lazos que ataron la estética exótica a la representación de culturas y geografías al margen de Occidente. Lo mismo con la representación de una alteridad adaptada a señas estéticas europeas, un proceso que, a través de la grafía y la imagen, promocionó combinaciones en las que lo étnico se integró a imaginarios como el urbano, el colonial, el militar y otros estilos nacidos en el marco de la modernidad occidental (véase la Figura 4). 
FIGURA 4. Fusión de estilos occidentales con lo "étnico" Fuente: La imagen 1 es parte de la colección de Louis Vuitton para el "Spring 2010 Ready to Wear". En ella se combina el estilo de la moda afro de los ochenta con la estética de algunas etnias de Norteamérica en la propuesta de bolso. Disponible en el artículo escrito por Mower

(2009). La imagen 2 es parte de la colección de Stella Jean para el

"Fall 2016 Ready to Wear". En ella se fusionan estampados inspirados en estéticas africanas con oficiales cascanueces. Disponible en el artículo escrito por Alessandra Codinha (2016). La imagen 3 es parte de la colección de Marcelo Burlon County of Milan. En ella se combina una estética urbana con símbolos que evocan estilos étnicos indoamericanos. Disponible en el artículo escrito por Flaccavento (2015). La imagen 4 es parte de la colección de Dimitri para el "Berlin Fall 2015". En ella se combinan cinturones que se representan como un tipo étnico con estilos que evocan diversos imaginarios, en este caso el ejecutivo. Disponible en el artículo escrito por Ana Finel Honigman (2015). La imagen 5 es parte de la colección de Marc by Marc Jacobs para el "Spring 2010 Ready to Wear". En ella se fusiona el estilo retro de los cincuenta con estampados que aluden a supuestas estéticas étnicas. Disponible en el artículo escrito por Phelps (2009).

21. Las identidades corporales ideales entendidas como estereotipos corpóreos que, valiéndose de la subjetividad que promueven sus estéticas, derivan

en procesos de identificación que conducen a los sujetos a asumir roles y posiciones sociales específicas (Esteban, 2004).
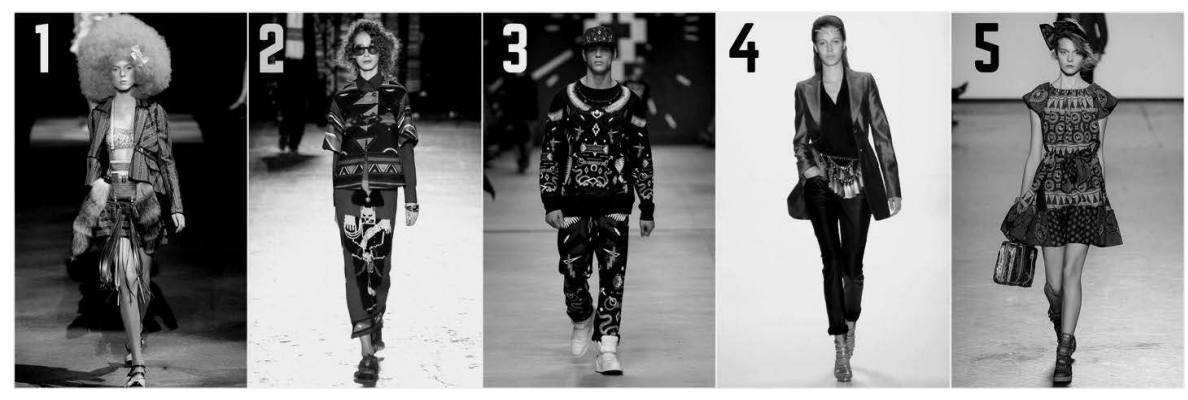

En otros casos, los semas relacionados con la naturaleza y el supuesto origen de la humanidad condenaron lo exótico a una dimensión temporal y espacialmente diferente: un "ahora" más atrás del presente y un "acá" más allá de Occidente. Las amazonas, símbolos de fiereza y depredación, contrastaron a la vez que complementaron el relato referido a la "pocahontización" de lo femenino, símbolo de docilidad y contemplación. El significado asociado a lo étnico se rigió a partir de procesos dialécticos donde relaciones como "el adentro y el afuera" en lo geográfico, "lo sobrio y lo vistoso" en lo estético, "lo normal y lo exótico" en lo identitario, "lo central y lo marginal" en lo económico y "lo adaptado y lo persistente" en lo político, dieron cuenta de lo estructural de la oposición semántica en relación con la idea de exotismo (véase la Cuadro 3).

La performatividad del cuerpo también fue muestra de estas relaciones. Al igual que con los objetos, estuvo profundamente asociada a la historicidad de los imaginarios que Vogue pretendió relatar. Las performances que dieron vida al cuerpo encarnaron las interpretaciones atribuidas a la feminidad y la masculinidad indoamericanas, dos tipos de identidades corporales ideales que reafirmaron antiguos conceptos en relación con la alteridad. ${ }^{21}$ Lo femenino imitó los valores de apacibilidad, fertilidad y contemplación que fueron asignados a una primera lectura de la mujer indoamericana (Dussel 1980, 2007), a lo que se añadieron analogías con deidades griegas y venus del renacimiento, ambos arquetipos de feminidad en el imaginario occidental. De esta forma, rasgos como proporciones armónicas, distensión del cuerpo y docilidad en la

Cuadro 3. Asociación de los semas que constituyen el exotismo en los discursos de las fashion weeks en Vogue

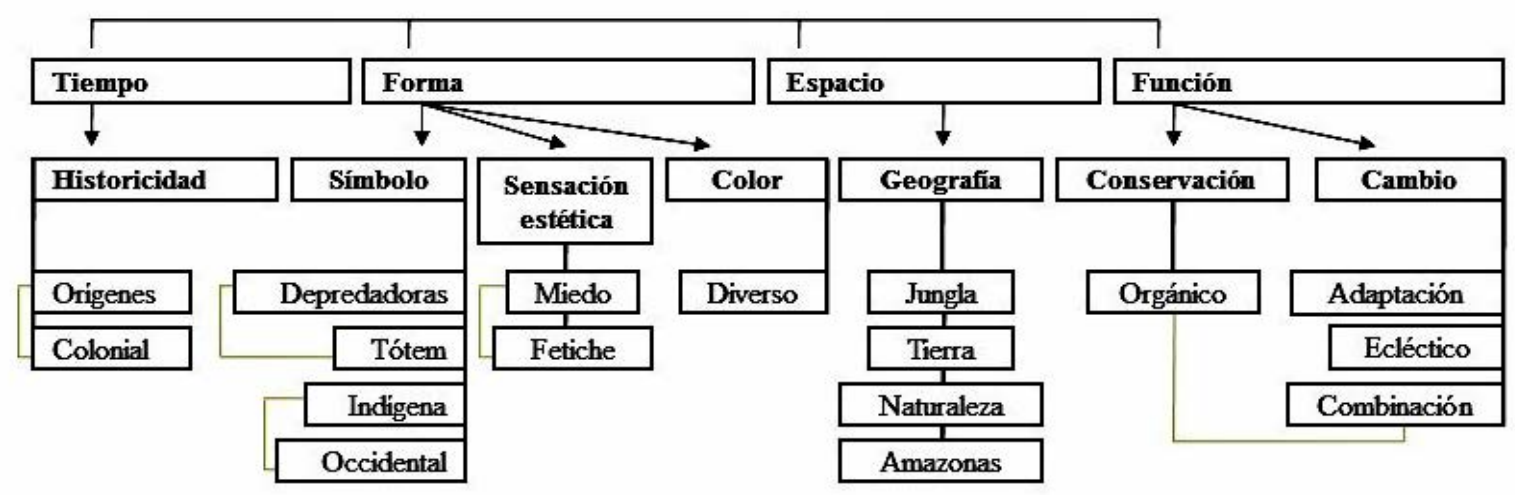

Fuente: Elaboración propia. Nota: Las líneas grises muestran las relaciones dialécticas entre los semas (orígenes vs. colonial; depredadoras vs. tótem; indígena vs. occidental; miedo vs. fetiche; orgánico vs. ecléctico, adaptación, combinación, etcétera). 

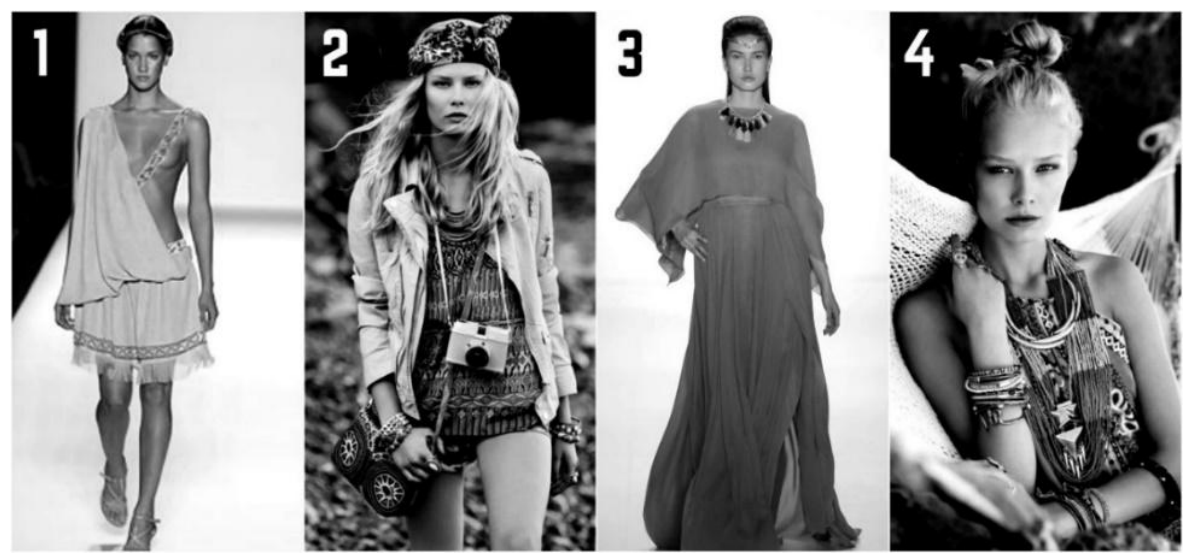

Figura 6. Venus y diosas ¿étnicas? Fuente: La imagen 1 forma parte de la colección de Sebastián Pons para el "Spring 2004 Ready to Wear”. Disponible en el artículo de Laird Borrelli-Persson (2003). Las imágenes 2 y 4 forman parte del contenido visual promocional al "ethnic chic" de la marca India Style. Disponibles en el artículo escrito por Flora González (2014). La imagen 3 forma parte de la colección de Dimitri para el "Berlin Fall 2015”. Disponible en el artículo escrito por Finel Honigman (2015).

expresión, se combinaron con fusiones de estilo que visibilizaron transFiguraciones entre ambos símbolos (véase la Figura 6).

También abundaron las performances que revivieron valores contrarios a los que se señalaron previamente, representaciones de imaginarios en los que la alteridad fue asociada a atributos como la ferocidad, la depredación y el cuestionamiento a la condición de humanidad. Estas propiedades se imputaron a un segundo tipo de feminidad, como fue el caso de las amazonas, pero, sobre todo, a la masculinidad insurrecta representada históricamente en arquetipos como los antropófagos caribes (Biord Castillo, 2006), los disformes ewaipanomas, los indómitos piel roja, etcétera. Las performances que hicieron posible este tipo de representaciones exaltaron rasgos comunes como la desproporción, la tensión y la fiereza en la expresión (facial y corpórea) los cuales, fueron acompañados por máscaras, pinturas corporales y objetos extravagantes que perturbaron la identificación del sujeto, especialmente la del rostro, unidad física por excelencia de aprehensión de las personas (Le Breton, 2010). De esta forma, se desdibujó el entendimiento de su humanidad, y con ello, la posibilidad de alcanzar mecanismos de identificación como los que se promovieron en el primer relato (véanse las imágenes 1, 2 y 3 de la Figura 7). ${ }^{22}$ En otros casos, la fiereza se expresó sin ningún rasgo de censura o desproporción, y le fueron imputados atributos que erotizaron su figura en favor de un diálogo con las primeras representaciones de lo femenino (es el caso de la imagen 4 de la Figura 7). ${ }^{23}$ Así, se generó una encrucijada en la que la armonía se canalizó hacia las performances donde las mercancías étnicas se promocionaron de la mano con arquetipos de feminidad occidental, mientras que la extrañeza estuvo dirigida a alteridades en que las diferencias fueron notablemente

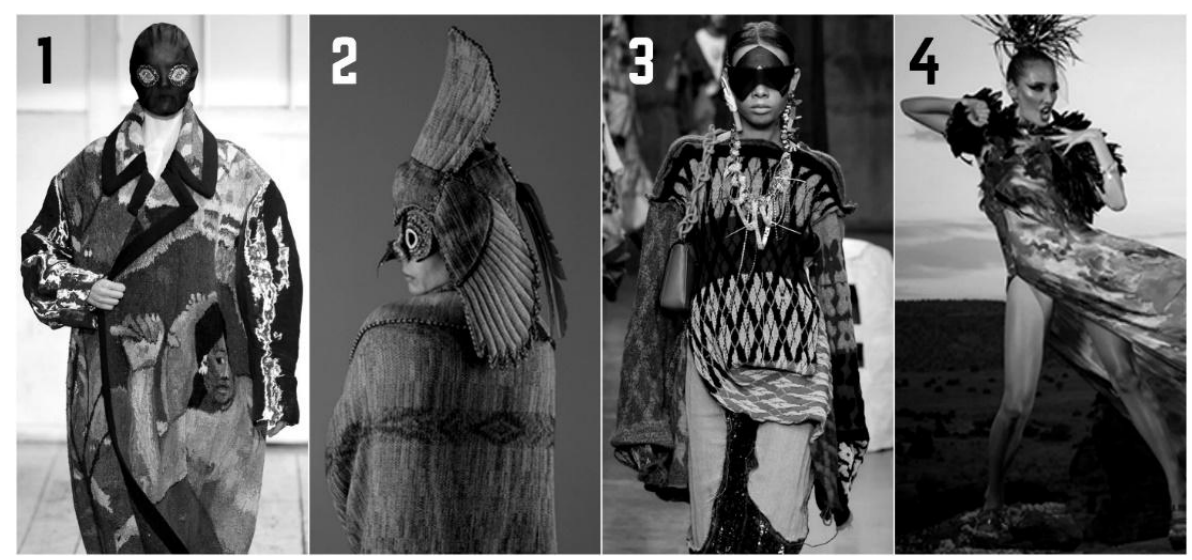

22. Al ser el rostro la carta de presentación del cuerpo, su desdibujamiento constituye un claro intento de desvirtuar la identidad y, en casos extremos, incluso la propia condición de humanidad (Le Breton, 2010).

23. La erotización es el proceso estético en el que la performance da cabida a sensaciones culturalmente asociadas al placer. En este sentido, las performances sometidas a procesos de erotización son, en el fondo, performances feminizadas; es decir, representaciones donde se exaltan cualidades o conductas asociadas a lo femenino: sensualidad, fertilidad, docilidad, abundancia, etcétera.

Figura 7. Masculinizados, incógnitos y exagerados Fuente: La imagen 1 pertenece a la colección de Maison Margiela para el "Spring 2014 Couture". Disponible en el artículo escrito por Tim Blanks (2014). Las imágenes 2 y 4 pertenecen a la promoción del "Native Fashion Now" organizado por el Museo Peabody Essex. Disponibles en National Museum of the American Indian (2017). La imagen 3 es parte de Matty Bovan para el "Fashion East 2017". Disponible en el artículo escrito por Mower (2017). 
24. [Traducción] “Diseñador textil estadounidense y europeo toma libremente de fuentes nativas, proclamando como propios los diseños de los navajo, paracas, mayas, kuna y aimara. Los diseños de huipiles mayas se ofrecen como patrones de costura 'Vogue original'. Los quilters norteamericanos reciben instrucciones paso a paso sobre cómo hacer sus propias molas para colchas, almohadas y vestidos.

Y así, los impulsos de apropiación vuelven a formar un círculo: los fabricantes de molas kuna toman nuestra tela que cortan, cosen y cambian en molas que tomamos y confeccionamos en nuestra ropa. Como James Clifford nos recuerda: 'el coleccionismo y el coleccionismo de cultura ahora tienen lugar dentro de un campo cambiante de contradiscursos, sincretismo y reapropiación, originados tanto en el exterior como en el interior"”. exacerbadas. Los puntos medios estuvieron ausentes pues, las performances del cuerpo y el sincretismo entre los objetos imposibilitaron la existencia de alteridades libres de políticas de occidentalización (adaptación/combinación con estéticas, símbolos o arquetipos occidentales) o exotización (exaltación de contrastes con Occidente).

\section{Dialéctica de lo glocal. Agencias, apropiaciones y resistencias en torno a la alta moda}

American and European textile designer freely take from native source, proclaiming as their own those designs draws from Navajo, Paracas, Mayas, Kuna and Aimara originals. Maya huipils designs are offered as "Vogue original" sewing patterns. North American quilters are given step-by-step instructions on how to make their own molas for quilts, pillows, and dresses. And so, the impulses of appropriation come full circle again: Kuna mola makers take our cloth which they cut, sew, and refashion into molas which we take and fashion into our on clothes. As James Clifford reminds us "art collecting and culture collecting now take place within a changing field of counter discourses, syncretism, and reappropiation, originating both outside and inside.

(Berlo, 1996, p. 452). ${ }^{24}$

Entendidas las contradicciones que tuvieron lugar en el plano estético y simbólico, es preciso reconocer un tercer tipo de contradicción, uno que acogió y redimensionó los dos planos anteriores. La monopolización de lo étnico en el sistema de alta moda derivó en contradicciones que pusieron en tela de juicio no solo la performatividad étnica, sino también la existencia de los grupos étnicos que se identificaron con algunos de los símbolos allí expresos. Las disputas no solo tuvieron lugar en la estética o en la semántica; también lo tuvieron en el marco de un proceso de mundialización que removió la distribución de los marcadores señalados en la introducción, entre ellos, objetos y estéticas que fueron apropiadas a través de las performances promocionadas por la moda. El elogio a lo diverso en el sistema de alta moda toma sentido cuando los significantes de estos marcadores subordinan su existencia a la condición de mercancía, por lo que, aunque muchos han sido los conflictos entre grupos étnicos concretos - como los navajo, paracas, mayas, kuna y aimara, por mencionar casos mediáticos - y marcas de alta moda, estos han sido minimizados por el carácter ecléctico asignado a una porción importante de sus tendencias. La mayoría de los símbolos étnicos en las performances de alta moda no responden a estéticas íntegras emergidas de sistemas culturales particulares; de hecho, las constantes combinaciones degradan la certeza respecto de lo que se expresa. Sin embargo, esta ausencia de certezas no impidió la emergencia de resistencias que, en los últimos años, cobraron importancia en las disputas por los derechos de autor respecto de la inventiva y saberes propios de los pueblos indígenas de América; asimismo, en las tensiones que emergieron del reclamo dirigido a la representación que se imputó al imaginario indoamericano desde esta plataforma.

Icónico fue el caso de apropiación dirigida hacia los artefactos culturales navajo, grupo étnico de los EE.UU., que, como indica Kathy M'Closkey (2014), es larga data y fue resultado de un matrimonio forzado entre indígenas y empresarios donde dominó un "script neglects the politico-economic domain and omits 
weavers' narratives". ${ }^{25}$ Los navajo se hicieron sentir en los medios de comunicación manifestando su disgusto hacia la naturaleza de las representaciones dadas a su cultura por algunas marcas de alta moda, es el caso de Chanel y Victoria's Secret a través de colecciones como "Métiers d'Arts". En palabras de Erny Zah, representante del pueblo navajo, han "tenido que pasar por muchas atrocidades para sobrevivir y asegurar la continuación de [su] modo de vida, [por lo que] cualquier mofa, ya sea Victoria's Secret o Halloween, es escupir sobre [su] cultura" (Ximénez, 2013).

La molestia radicó en el sentido dado a su representación en la pasarela pues, en el marco de severas disputas por el territorio con el gobierno de los EE.UU., la performatividad navajo en la alta moda ignoró los problemas reales que estos enfrentan como pueblo, y perpetuó estereotipos errados que reivindican poco sus intereses en la historia. El problema se originó a partir de la apropiación del tocado de plumas que se muestra a continuación (véase la Figura 8), el cual constituye un símbolo de poder que identifica a los jefes de guerra de dicho pueblo. El uso estético conferido al tocado de plumas en la performance de alta moda no reflejó el sentido que convierte el tocado en un marcador de etnicidad entre los navajos. De esta forma, la apropiación del tocado fue tomada como una desnaturalización del objeto y muestra de poco respeto hacia su cultura, con lo cual se sumaron así los inconvenientes que tuvieron que ver con los derechos de autoría, uso y explotación de símbolos y objetos (como el tocado) al hallarse registrados por la marca "Navajo". Destacaron también las presiones económicas de sectores indígenas que se vieron afectados por el redireccionamiento del consumo hacia otros tipos de mercado, consecuencia del auge de las imitaciones y de la promoción de sus productos a través de mercancías ofertadas por marcas de mayor prestigio.

En Guatemala, Panamá y Colombia recrudecieron las disputas en relación con el plagio artesanal de los tejidos e indumentarias tradicionales de pueblos como los mayas y kunas (EtnoMAT, 2016), en especial, la apropiación de la mola (arte textil kuna) por marcas internacionales como Maiyet, Nicole Miller y las colecciones de Esteban Cortázar en la moda parisina de Colette (véanse los artículos de Codinha, 2015; Wright, 2017 y Vogue, 2017), así como por diseñadores locales como Helene Breebaart, Paola Argüello, Verónica Ángel y otros. Esta situación propició la articulación de diversas organizaciones (Ministerio de Comercio e Industrias de Panamá, Dirección General de Artesanías de Panamá, EtnoMAT, etcétera) en defensa de la propiedad intelectual de los tejidos kuna. Así, en noviembre de 2016 se celebró el Primer
25. [Traducción] “guión que descuida el dominio políticoeconómico y omite las narraciones de los tejedores".

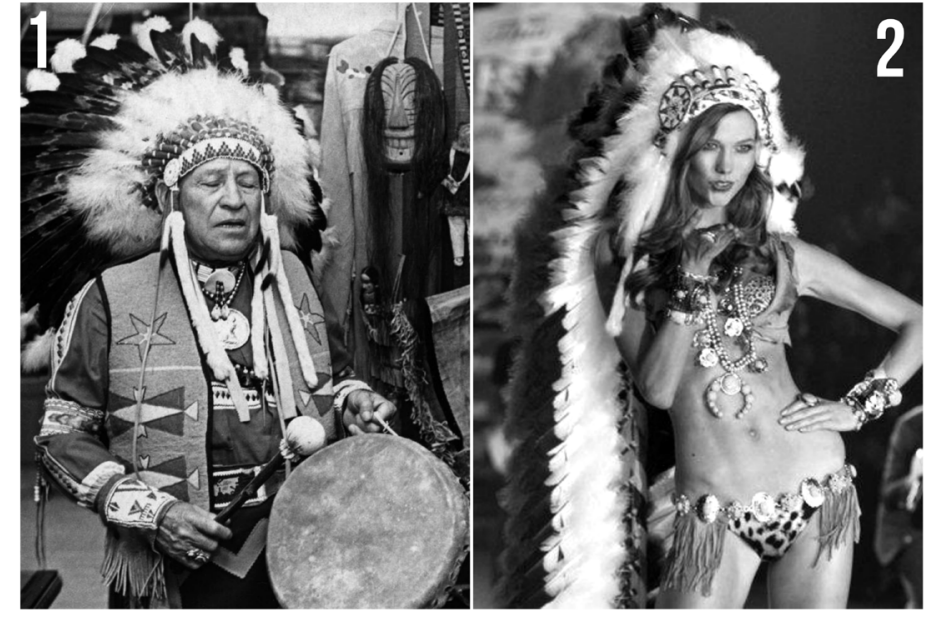

Figura 8. Usos del tocado de plumas navajo Fuentes: La imagen 1 muestra el uso del tocado de plumas a lo interno del grupo étnico. Disponible en el artículo escrito por Alexandra Jane (2012). La imagen 2 muestra el uso del tocado de plumas en un desfile de la marca Victoria's Secret. Disponible en el artículo escrito por Ximénez (2013). 
26. Como resultado de esta articulación surgió la Ley 20 de 2000, que reconoce la mola como propiedad colectiva del pueblo kuna. En Panamá, la explotación de la mola solo la pueden hacer los artesanos kunas.

27. Bordado mixe característico por tener estrellas en el frente de la blusa y en los puños de las mangas.

28. Activistas mexicanos subieron una petición al sitio web (www. change.org) dirigida a la OMPI, a la Organización Internacional del Trabajo (OIT) y a la Comisión

Nacional para el Desarrollo de los Pueblos Indígenas de México, en favor de la protección de los derechos de autor de los huipiles.
Encuentro Binacional de Líderes Mujeres Artesanas Kunas y Autoridades Locales, al cual asistieron más de 150 mujeres kunas de las comarcas Guna Yala, Madungandí, Wargandí y Tagarkunyal, en Panamá, y la comunidad caimán, en Colombia, con el objetivo de reevaluar la significación de la mola entre los miembros del pueblo kuna y buscar estrategias de protección ante las crecientes apropiaciones. La organización kuna ha avanzado en dos direcciones. Por un lado, en respuesta a la preocupación por los cambios de función y significado del arte textil kuna como marcador de etnicidad (representación de su visión de mundo y cosmogonía), Y, por otro lado, como respuesta a una preocupación comercial pues, como señaló Plácido Pascual, miembro kuna y productor de molas, "los indígenas no tienen medios para invertir y; ellos, los grandes empresarios, explotan nuestros modelos y hacen su negocio [...] hay muchos vendedores" (La Prensa, 2002). Las respuestas de la organización étnica apunta a medidas como la nominación de la mola a la lista de bienes Patrimonio Cultural de la Humanidad reconocida por la UNESCO, así como al fortalecimiento de articulaciones con el gobierno nacional a fin de sancionar futuras apropiaciones. ${ }^{26}$

Otro caso controversial tuvo lugar en México, en las denuncias dirigidas por autoridades del municipio Santa María Tlahuitoltepec y miembros del pueblo mixe hacia la diseñadora francesa Isabel Marant y la marca Antik Batik por comercializar el "huipil" sin otorgar créditos o beneficios económicos a dicho pueblo. ${ }^{27}$ "Se deben vender, pero debe ser la confección, las ganancias y las atenciones para el pueblo mixe, no para otra persona, no para otras empresas", dijo Fidel Pérez Díaz, integrante del cabildo (EFE, 2015; Mérida, 2015). Desde entonces, autoridades locales y miembros del pueblo mixe se han organizado en función de elevar su reclamo a instancias nacionales, como la Comisión de Asuntos Indígenas del Senado de México, e internacionales, como la OMPI y la Unesco, en favor de exigir reconocimiento y regalías por la comercialización de los huipiles. ${ }^{28}$ Destaca también la indignación de colombianos "criollos" que, valiéndose de los discursos nacionalistas que apropiaron lo indígena como sello de una identidad nacional, expresaron su molestia ante la comercialización de objetos étnicos sin hacer mención de su origen, fue el caso de los bolsos y tejidos wayuu en mercados europeos (El espectador, 2014). El alcance comunicacional en torno a estos casos despertó un llamado de conciencia en relación con el problema de la apropiación cultural en la moda, y complejizó el tejido de instituciones que han sumado

su voz a la crítica (Figura 9).

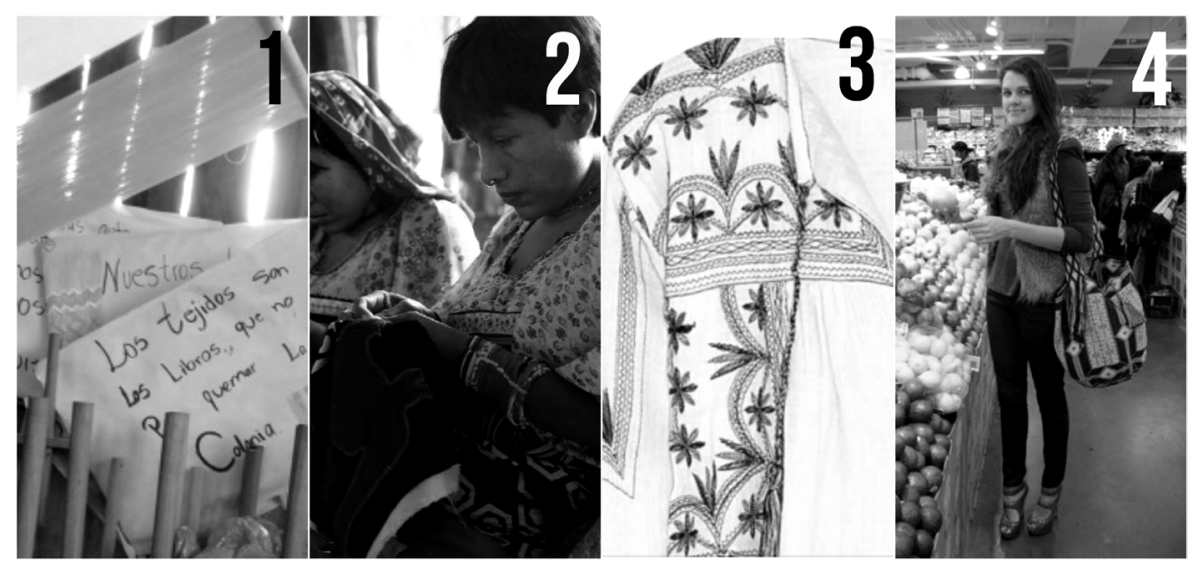

Figura 9. Controversias en relación con lo "étnico" Fuentes: Imagen 1 "Los tejidos son los libros que no pudo quemar la Colonia". Disponible en el artículo escrito por EtnoMAT (2016). La imagen 2 muestra la confección de la "mola" por mujeres kuna. Disponible en el artículo escrito por Karen Bernal (2016). La imagen 3 muestra un "huipil", arte textil mixe. Disponible en Emiliano Villalba (2015). La imagen 4 forma parte de la promoción de Vogue hacia los bolsos wayuu como contenedor de compras ideal para

"chicas de ciudad elegantes". Disponible en el artículo escrito por Virginia Tupker (2009).

$$
\text { . }
$$


Circunstancias como el auge del multiculturalismo en los discursos artísticos, científicos y académicos de finales del siglo XX hasta el presente; la vigencia de proyectos políticos de izquierda y su apología a la diversidad; el florecimiento de movimientos sociales y reivindicaciones hacia grupos afrodescendientes e indígenas; a lo que se suma la realización del Mundial de Fútbol 2010 en Sudáfrica, 2014 en Brasil y los Juegos Olímpicos 2016 en Río de Janeiro, ${ }^{29}$ generaron una reacción en cadena en la que estéticas, símbolos, formas y colores expresaron la conmoción al multiculturalismo en la promoción dada a lo étnico en la moda, y tejieron un universo de (1) controversias, en relación con los derechos y agravios asociados a la apropiación de los objetos étnicos; (2) reivindicaciones, dirigidas desde movimientos sociales locales, regionales y multinacionales; (3) políticas de identidad, subyacentes a los discursos nacionalistas de la izquierda latinoamericana y; (4) proyectos económicos, asociados a la expansión de transnacionales europeas y norteamericanas, así como a la internacionalización de los países latinoamericanos como mano de obra barata, todo lo cual tributa a posicionar el imaginario de lo étnico en el top de las tendencias de moda en lo que va de siglo. ${ }^{30}$

\section{Consideraciones finales}

La moda subyace en lo más hondo de la experiencia moderna, y su sistema de ideas e instituciones constituye un todo en el que se entrelazan capitales, subjetividades y sentidos en escenarios que desdibujan las fronteras entre lo viejo y lo nuevo, tradición e innovación. Ambivalentes han sido las fuerzas que robustecieron la idea de un "otro" que, por medio de mercancías y performances, se promueve a formar parte de sí. Ese "otro" ya no es distante e indómito, puede hallarse en diseños y colecciones de moda, así como en centros comerciales y demás espacios sujetos a su influencia. Incluso, puede hallarse en el museo. Recientemente, las lecturas dadas por la moda a la cuestión étnica tuvieron cabida en el museo, donde se representaron en diseños que mostraron "el alcance visual, la expresión creativa y el matiz político de la moda nativa americana" (National Museum of the American Indian, 2017, s.p). El Museo Peabody Essex y el Museo Nacional del Indio Americano sirvieron de auspiciantes a la realización del Native Fashion Now, celebrado en EE.UU. de febrero a septiembre del 2017. En él se expusieron un conjunto de colecciones que mostraron la "inventiva" de la moda étnica en los últimos cincuenta años, desde los comienzos del Native American Style en los años setenta, hasta el reemerger del ethnic chic en los últimos años. Este acontecimiento dio cuenta de la trascendencia de las lecturas ofrecidas por la moda a la cuestión de la alteridad, y formalizó sus representaciones al presentarse en contextos sociales con una tradición histórica y simbólica como la que, en este caso, subyace a los museos; sin duda, una connotación diferente a la que se asocia a las tiendas, revistas y pasarelas. $^{31}$

Los recientes conflictos en relación con la apropiación cultural y el carácter muchas veces lascivo de sus representaciones evidencian que en el presente son otros los escenarios de lucha. Las estéticas y performatividades de lo étnico quedaron presas del viejo mito en torno al buen y mal salvaje, y no reflejan los actuales dilemas que aquejan a los grupos étnicos. Son insuficientes los esfuerzos de aliados y mediadores culturales (colectivos, organizaciones, ONGs, etcétera) orientados a la protección del patrimonio cultural indígena. Por su parte, las agencias indígenas en los medios de comunicación continúan siendo periféricas, por lo que muchos de estos conflictos terminan no siendo expresión de sus intereses. En los últimos años, las iniciativas por una moda
29. El “boom" en relación con lo étnico no quedó suscrito únicamente al campo de la moda; de hecho, en los últimos años, los más diversos géneros musicales, así como las promociones a todo tipo de productos se valieron de imaginarios asociados a la diversidad étnica.

30. En el caso latinoamericano destacan fenómenos como lo que Rey Cadavid (2016) denominó la expansión del “Evo Look” el cual, según consideraciones del autor. formó parte del caldo de cultivo aprovechado por la moda de alto y bajo costo. También la implementación de políticas económicas como "Perú Moda" - un ícono de las políticas económicas oficiales asociadas a la moda, aunque fenómenos del mismo tipo se gestaron masivamente de manera dispersa o extra oficial- en la que empresas peruanas abocadas al sector textil fortalecieron sus lazos con empresas europeas a fin de posicionar al Perú como un proveedor mundial de prendas y accesorios de calidad, para destacar la producción de prendas indígenas hechas con lana peruana (La República, 2016).

31. La representación de la alteridad en los museos tradicionalmente estuvo ligada al surgimiento del coleccionismo arqueológico y objetos curiosos asociados a sistemas culturales diferentes de Occidente. La penetración de las representaciones dadas por la moda es un fenómeno bastante reciente. 
32. La generación de "proyectos con impacto positivo en minorías" constituye uno de los principios fundamentales de la moda ética y sostenible. Véase: http://www.modaetica. com/principios_detalles.php ética y sostenible han ganado fuerza, y la Fashion Week Miami 2018 fue ejemplo de ello "Abrigos hechos de botellas de plástico rescatadas del mar, chaquetas reflectantes que se convierten en tiendas de campaña para refugiados y códigos que permiten saber las manos por las que ha pasado [una prenda...]" fueron algunas de las propuestas presentadas (EFE, 2018). Otros acontecimientos como la creación de la Eco Fashion Week Australia en 2017; y el posicionamiento del eslogan "moda ética y sostenible" como tema central de las fashion week realizadas en Nueva York, Berlín y Nueva Zelanda en 2018 dan cuenta de este proceso. No obstante, el énfasis se ha colocado en la sostenibilidad ecológica por encima del compromiso con la etnodiversidad. ${ }^{32}$

Las controversias en relación con la apropiación cultural y la avanzada de iniciativas de responsabilidad ética y social en el sistema de alta moda exigen una discusión de las relaciones que establecen sus marcas con las poblaciones que involucran en su proceso comercial y creativo. Los valores estéticos asociados a lo bélico y erótico posicionaron lo étnico en dos extremos de un discurso lineal, que brindó al exotismo la posición de un valor único y aplastante. Sin embargo, es preciso decir que este sello discursivo constituyó más una política editorial de Vogue que un consenso irrestricto por parte de las firmas y marcas de alta moda, aunque no por ello estuvieron exentas de coincidencias en su representación. Este tratamiento avivó críticas, tanto a la semántica del discurso, como a la exclusión de los grupos étnicos de las dinámicas y beneficios económicos que devinieron de la comercialización de los símbolos con que se identificaron, aspecto que todavía queda por estudiarse, ya que, aunque el propósito de este trabajo radicó en el estudio de las representaciones y agencias movidas por la crítica, la integración y/o segregación de los grupos étnicos de las dinámicas de mercado constituyó también una fuente frecuente de reclamos.

\section{Notas}

5. ETNOMat es un proyecto vinculado al Departament d'Antropologia Social de la Universitat de Barcelona que tiene como objetivo investigar los vínculos entre la cultura material, la identidad y la propiedad intelectual en diferentes sociedades contemporáneas de América, África y Europa. El proyecto fue aprobado por el European Research Council y financiado por el Ministerio de Economía y Competitividad, y consiste en una investigación comparada sobre las expresiones culturales tradicionales, en particular sobre las cuestiones sociales, económicas y políticas que plantea su producción, uso y comercialización, así como su conceptualización como una propiedad intelectual. Visítese el portal web: https://etnomatblog.wordpress.com/ (En página 94.)

10 En un estudio de mi autoría dedicado a analizar el éxito de estos grupos comerciales en países latinoamericanos y caribeños, muestro cómo el "fin de las ideologías", el auge de las políticas neoliberales en los años noventa y más recientemente, acontecimientos como el crecimiento de la economía, el incremento de la clase media y la segunda expansión del neoliberalismo en los años dos mil en algunos países de América Latina, guardaron relación con la penetración de las marcas asociadas a Inditex (Zara, Stradivarius, Pull \& Bear, Massimo Dutti, Bershka, Uterqüe, Oshyo), H\&M y Mango desde 1992 hasta el presente. También muestro cómo, pese a los marcos ideológicos oficializados en gran parte de estos países - en los noventa el neoliberalismo, en los dos mil los discursos de izquierda de países como Venezuela, Brasil, Ecuador, Argentina y 
Perú-, la expansión de estos grupos logró superponerse a escenarios diferentes pues, las coyunturas facilitaron su penetración tanto en los escenarios de debacle como en los escenarios de auge. La asociación de la moda europea al imaginario de lo "moderno" no entorpeció ni las promesas de progreso enarboladas por los sectores que auspiciaron la apertura al capital extranjero ni el figurado éxito de los proyectos nacionales coligados a la izquierda. En ambos casos, la moda europea sirvió de certificación al progreso, lo que aseguró su incursión en el difícil escenario de los noventa y su crecimiento en el cándido escenario de los dos mil, cuando la clase media legitimó su estatus a partir del consumo de las mercancías ofertadas por estos grupos (Mora, 2018). (En página 99.)

11 Jean Borgatti (2015) narra cómo textiles y estéticas Yoruba (africanas) han sido explotadas en el marco de la alta moda europea a través de los diseños y mercancías de marcas como la de Ade Bakare's. En otro trabajo, las autoras Christine Delhaye y Rhoda Woets (2015) discuten el fenómeno de la etnicidad africana presente en las representaciones de Vlisco, una corporativa textil africana cuyas mercancías se consumen en las principales ciudades de Europa y del mundo. En el caso chino, Timothy Lindgren (2015) relata como plataformas como las fashion weeks y Vogue han penetrado en los patrones de consumo en China y en el mundo, reproduciendo la visión eurocéntrica sobre la modernidad, belleza y supuestos atributos de la etnicidad asociada a lo "chino". Como estos, otras investigaciones dan cuenta de la explosión comercial asociada a la moda en torno los estereotipos mencionados. (En página 99.)

13 Las burkas (hijab) encabezan los accesorios que estereotipan la moda árabe en las pasarelas. Plumas, ruanas (ponchos) y máscaras constituyen algunos de los objetos que comúnmente representan las culturas amerindianas. Para el caso nórdico destacan los abrigos de pieles; mientras que el estereotipo africano se vale de figuras de animales, turbantes y tejidos coloridos. La seda roja no puede faltar en las representaciones sobre lo chino; mientras que el estereotipo hindú suele hacer gala del sari (pieza larga de tela que suele envolverse en forma diferente alrededor del cuerpo) y los salwar kameez (pantalones sueltos que se vuelven angostos en los tobillos). (En página 99.)

14 Stella Jean ha colaborado con la iniciativa de moda ética impulsada por el Centro de Comercio Internacional. Muchos de sus tejidos se obtienen de forma sostenible, son confeccionados a mano y se destinan a ayudar a trabajadores del comercio en comunidades desfavorecidas del Caribe y de África. A menudo trabaja con artesanos haitianos y africanos impulsando empresas comerciales y comunidades locales autosostenibles; asimismo, concibe como posible la simbiosis de modelos de desarrollo locales y regionales a la par del éxito de las marcas de alta moda. Desde sus inicios, ha sido enfática en la necesidad de retribuir a las comunidades locales que le sirven de inspiración. Actualmente constituye una de las marcas baluartes del movimiento Moda Ética, el cual plantea la necesidad de voltear la vista a las comunidades y posicionar a la moda como un agente de cambio de sus realidades. Su marca tiene sede en Roma, aunque está presente en tiendas de todo el mundo. Visítese el portal web: https://www.stellajean.it/ (En página 100.) 


\section{Q Referencias bibliográficas}

"Amodio, E. (1997). El valor de las cosas. Sentido y valor de la artesanía indígena en Venezuela. Estudio de caso y temas. Caracas: Consejo Nacional de Cultura.

" Amodio, E. (1998). Manufactos. Sobre la vida, transformación y muerte de los objetos indígenas. I Coloquio Nacional de Artesanías y Arte Popular. Caracas: Universidad Central de Venezuela, Consejo Nacional de la Cultura y Dirección Nacional de Artesanías.

" Bari, M. C. (2001). La cuestión étnica: Aproximación a los conceptos de grupo étnico, identidad étnica, etnicidad y relaciones interétnicas. Cuadernos de Antropología, 16: 149-163.

» Barth, F. (1976). Los grupos étnicos y sus fronteras. La organización social de las diferencias culturales. México D.F.: Fondo de Cultura Económica.

» Bartlett, D. (2015). “In Russia, At Last and Forever: The First Seven Years of Russian Vogue”. Fashion Theory, 10(1-2): 175-204.

"Bartra, R. (2011). El mito del Salvaje. México D.F.: Fondo de Cultura Económica.

" Bauck, W. (2016). Olivier Rousteing opens up about racial discrimination, social media profitability and launching his own line. Recuperado de https://fashionista.com/2016/10/olivierrousteing-met

"Berlo, J. C. (1996).Beyond Bricolage: Women and Aesthetic Strategies in Latin American Textiles. En: M. Schevill, J. C. Berlo y E. B. Dwyer (eds.). Textile Traditions of Mesoamerica and the Andes: An Anthology. Texas: Texas University Press. pp. 461-503.

» Bernal, K. (2016). La mola, un arte para la humanidad. Recuperado de http://laestrella. com.pa/estilo/cultura/mola-arte-para-humanidad/23977396

» Biord Castillo, H. (2006). Antropofagia y crítica histórica: Los Caribes vistos por Julio César Salas. En: H. Biord Castillo (ed.). Los Indios Caribes. Estudio sobre el origen del mito de la antropofagia. Mérida: Fundación Julio Cesar Salas y Publicaciones del vicerrectorado académico de la Universidad de los Andes. pp. 9-36.

"Blanks, T. (21 de enero, 2014). Spring 2014 Couture. Maison Margiela. Recuperado de http://www.vogue.com/fashion-shows/spring-2014-couture/maison-martin-margiela

"Borgatti, J. (2015). Why Africa? Why now? The designs of Ade Bakare. International Journal of Fashion Studies, 2(1): 99-113.

"Borrelli-Persson, L. (18 de septiembre, 2003). Spring 2004 Ready-to-Wear. Sebastian Pons. Recuperado de http://www.vogue.com/fashion-shows/spring-2004-ready-to-wear/ sebastian-pons

" Bourdieu, P. (1993). The Field of Cultural Production. Cambridge: Polity.

» Bur, A. (2013). Moda, estilo y ciclo de vida de los productos de la industria textil. Cuadernos del Centro de Estudios en Diseño y Comunicación, 45: 143-154.

"Codinha, A. (20 de julio, 2015). Exclusive: One-of-a-Kind Summer Clutches Straight from Colombia. Recuperado de http://www.vogue.com/article/moda-operandi-exclusive-mola-sasa-clutches

" Codinha, A. (28 de febrero, 2016). Fall 2016 Ready-to-Wear. Stella Jean. Recuperado de http://www.vogue.com/fashion-shows/fall-2016-ready-to-wear/stella-jean

" Coseriu, E. (1977). Principios de semántica estructural. Madrid: Gredos. 
»De Asís, B. (2017). Highly Preppy. Otoño-Invierno 2016/2017. Recuperado de http://www. vogue.es/desfiles/otono-invierno-2016-2017-madrid-fashion-show-highly-preppy/11956

»De Bry, Th. (2003). América. Madrid: Editorial Siruela.

»Delhaye, C. y Woets, R. (2015). The commodification of ethnicity: Vlisco fabrics and wax cloth fashion in Ghana. International Journal of Fashion Studies, 2(1): 77-97.

»Dussel, E. (1980). Liberación de la mujer y erótica latinoamericana. Ensayo filosófico. Bogotá: Nueva América.

»Dussel, E. (2007). Para una erótica latinoamericana. Caracas: Ministerio del Poder Popular para la Cultura.

» EFE (1 de junio, 2018). La moda ética y sostenible se apodera de la Miami Fashion Week. Recuperado de http://www.eluniversal.com/estilo-de-vida/11016/la-moda-etica-y-sostenible-se-apodera-de-la-miami-fashion-week

» EFE (2 de diciembre, 2015). Los indígenas mixes defienden el valor intangible de sus bordados copiados en Francia. Recuperado de https://www.efe.com/efe/america/mexico/ los-indigenas-mixes-defienden-el-valor-intangible-de-sus-bordados-copiados-en-fran$\mathrm{cia} / 50000545-2779308$

»El Espectador (31 de marzo, 2014). Diseñadora española que habría copiado las mochilas Wayúu. Recuperado de http://www.elespectador.com/noticias/actualidad/disenadoraespanola-habria-copiado-mochilas-wayuu-articulo-483957

»English, B. (2013). A Cultural History of Fashion in the 2oth and 21st Centuries. From Catwalk to Sidewalk. Londres: Bloomsbury Academic.

»Esteban, M. L. (2004). Antropología del cuerpo. Género, itinerarios corporales, identidad y cambio. Barcelona: Bellatera.

» Etnomat (12 de septiembre, 2016). EtnoMAT en Guatemala. Recuperado de https://etnomatblog.wordpress.com/

»Finel Honigman, A. (20 de enero, 2015). Berlin Fall 2015. Dimitri. Recuperado de http:// www.vogue.com/fashion-shows/berlin-fall-2015/dimitri

» Flaccavento, A. (22 de enero, 2015). Fall 2015 Menswear. Marcelo Burlon County of Milan. Recuperado de http://www.vogue.com/fashion-shows/fall-2015-menswear/county-of-milan

»Frey, H. (1996). La mirada de Europa y el "otro" indoamericano. Revista Mexicana de Sociología, 58(2): 53-70.

» Gilij, F. ([1780-1784] 1995). Ensayo de historia americana: o sea historia natural, civil y sacra de los reinos, y de las provincias de tierra firme en la América Meridional. Bogotá: Editorial Sucre.

» González, F. (11 de junio, 2014). Reinventando el estilo étnico. Recuperado de http://www. vogue.es/moda/dress-for-less/articulos/tendencia-dress-for-less-de-inspiracion-etnicay-bohemia/19721

" Gumilla, J. ([1741] 1944). El Orinoco llustrado. Historia natural, civil y geográfica de este gran río. Tomo I. Bogotá: Biblioteca Popular de la Cultura Colombiana y Banco de la República.

» Guzmán Marín, F. (2000). La trágica experiencia de la alteridad. Michoacán: Universidad Michoacana de San Nicolás de Hidalgo.

» Hartley, J. (2009). Fashion as consumer entrepreneurship: Emergent risk culture, social network markets, and the launch of Vogue in China. Chinese Journal of Communication, 2: 61-76. 
» Jane, A. (23 de mayo, 2012). Navajo mood. Recuperado de https://fashionalmanac.wordpress.com/2012/05/23/navajo-mood/

"La Perla, R. (17 de febrero, 2017). American Originals in Fashion on Display. Recuperado de https://www.nytimes.com/2017/o2/17/fashion/native-american-indian-new-york-fashion-week.html?_r=o

"La Prensa (2002). La piratería perjudica arte kuna. Recuperado de https://impresa.prensa.com/opinion/pirateria-perjudica-arte-kuna_o_680931979.html

"La Republica (23 de abril, 2016). Perú Moda es un nuevo peldaño para el éxito de las exportaciones textiles. Recuperado de http://larepublica.pe/impresa/economia/762138-perumoda-es-un-nuevo-peldano-para-el-exito-de-las-exportaciones-textiles

»Le Breton, D. (2010). Antropología del cuerpo y la modernidad. Buenos Aires: Nueva Visión.

" Lindgren, T. (2015). How do Chinese fashion designers become global fashion leaders? A new perspective on legitimization in China's fashion system. International Journal of Fashion Studies, 2(1): 63-75.

" Lipovetsky, G. (1990). El imperio de lo efímero. La moda y su destino en las sociedades modernas. Barcelona: Anagrama.

》 Marcuse, H. (1983). Eros y civilización. Madrid: SARPE.

» Marriott, H. (20 de enero, 2015). Entrevista. De Kardashian a la alta costura: cómo Balmain consiguió su zumbido del siglo XXI. Recuperado de https://www.theguardian.com/fashion/2015/jan/20/kardashian-couture-balmain-buzz-olivier-rousteing-fashion-socialmedia-star

" Mayer Celis, L. (2016). Aceptación y negociación simbolicas en el tumult imperial de Carlos V (1559). En: P. Gonzalbo Aizpuru y L. Mayer Celis (eds.). Conflicto, resistencia y negociación en la historia. Mexico D.F.: El Colegio de México. pp. 41-69.

» Menkes, S. (2 de marzo, 2017). Balmain se pasa al lado salvaje. Recuperado de http://www. vogue.es/suzy-menkes/articulos/suzy-menkes-paris-otono-invierno-2017-2018-balmain $/ 28542$

» Miller, D. (2009). Materiality: An introduction. En: D. Miller (Comp.). Materiality. Durham: Duke University Press. pp. 1-50.

" Moeran, B. (2004). Women's Fashion Magazines: People, things, and values. En: C. A. Werner y B. Duran (Eds.). Values and Valuables: From the Sacred to the Symbolic. Lanham: Altamira Press. pp. 257-281.

" Moors, A. (2014). STEREOTYPES. The Misrepresentation of Native Americans in Fiction. (tesis de grado), Universidad de Utrecht, Facultad de Humanidades, Utrecht, Paises Bajos.

» Mora, J. (2018). Economía, política y consumos culturales. Apuntes para una historia de la moda retail europea en América Latina y el Caribe (1992-2015). Presente y Pasado. Revista de Historia, 23(45), 107-129.

" Mower, S. (21 de febrero, 2017). The top 10 shows of London's Fall 2017 Collections. Recuperado de http://www.vogue.com/article/ready-to-wear-fall-2017-collections-best-oflondon-fashion-week-recap

"Mower, S. (3 de octubre, 2015). Spring 2016 Ready-To-Wear. Junya Watanabe. Recuperado de https://www.vogue.com/fashion-shows/spring-2016-ready-to-wear/junya-watanabe

"Mower, S. (6 de octubre, 2009). Spring 2010 Ready-To-Wear. Louis Vuitton. Recuperado de https://www.vogue.com/fashion-shows/spring-2010-ready-to-wear/louis-vuitton 
» Mower, S. (9 de julio, 2002). Fall 2002 Couture. Ungaro Couture. Recuperado de http:// www.vogue.com/fashion-shows/fall-2002-couture/ungaro-couture

» Mérida, M. (20 de noviembre, 2015). Esto es lo que tienes que saber sobre el caso de supuesto plagio protagonizado por Isabel Marant. Recuperado de https:/www.vogue.es/ moda/news/articulos/caso-de-plagio-isabel-marant-blusa-de-tribu-indigena/24117

» M'Closkey, K. (2014). Navajo (Diné) Weavers and Globalization: Critiquing the Silences. Textile Society of America Symposium Proceedings, s.p. 14th Biennial Symposium. Recuperado de http://digitalcommons.unl.edu/cgi/viewcontent.cgi?article=1913\&context=tsac onf

» National Museum of the American Indian (2017). Native Fashion Now. Recuperado de http://nmai.si.edu/explore/exhibitions/item/?id=954

»Perez-Serrabona, M. (s.f.). Las pasarelas de moda como escenificación arquitectónica. (Tesis de grado) Universidad Politécnica de Madrid, Facultad de Arquitectura, Madrid, España.

» Phelps, N. (14 de septiembre, 2009). Spring 2010 Ready-to-Wear. Marc by Marc Jacobs. Recuperado de http://www.vogue.com/fashion-shows/spring-2010-ready-to-wear/marcby-marc-jacobs

»Phelps, N. (21 de enero, 2014). Spring 2014 Couture. Valentino. Recuperado de http://www. vogue.com/fashion-shows/spring-2014-couture/valentino

» Rey Cadavid, S. (2016). Renaciendo con Evo: Política, moda y cultura indígena en la era global. (Tesis de maestría), Universidad Nacional de Colombia, Facultad de Ciencias Humanas, Bógota, Colombia.

》Rodríguez, R. (19 de noviembre, 2014). Marcelo Burlon, el hombre hecho marca. Recuperado de https://elpais.com/elpais/2014/11/28/eps/1417175355_503018.html

»Sahagún, B. ([1569] 1938). Historia general de las cosas de Nueva España. Tomo I y II. México D.F: Editorial Pedro Robredo.

»Soley-Beltran, P. (2015). Pride and Glamour on the Catwalk. Fashion Models as National and Ethnic Icons. En: U. Merkel (Ed.). Identity Discourses and Communities in International Events, Festivals and Spectacles. Nueva York: Palgrave y Macmillan. pp. 207-226.

»Songer, C. M. (2014). Branding Luxury: Japan, China, and Vogue. (Tesis de grado), Universidad de Duke, Trinity College of Arts and Sciences, Carolina del Norte, Estados Unidos.

» Tarlo, E. (200o). Fashion fables of an urban village. En: Development. Critical concepts in the social sciences. Identities, representations, alternatives. Londres: Routledge. s.p.

» Thacker, S. (13 de abril, 2012). Wear the trend: tribal. Recuperado de http://www.vogue.in/ content/wear-trend-tribal/\#wear-the-trend-tribal

» Trouillot, M.-R. (2003). Global Transformations. Anthropology and the Modern. Nueva York: Palgrave Macmillan.

》Trouillot, M.-R. (2011). Moderno de otro modo. Lecciones caribeñas desde el lugar del salvaje. Tabula Rasa, 14: 79-97.

» Tupker, V. (24 de noviembre, 2009). Wear It Now: Tribal Totes. Recuperado de http://www. vogue.com/article/vd-wear-it-now-tribal-totes

» Twigg, J. (2010). How does Vogue negotiate age?: Fashion, the body, and older woman. Fashion Theory, 14(4): 471-490.

»Van Der Laan, E. y KUIPERS, G. (2016). Creating aesthetic, institutional and symbolic boundaries in fashion photo shoots. International Journal of Fashion Studies, 3(1): 47-68. 
»Villalba, E. (23 de noviembre, 2015). El escándalo del plagio contra Isabel Marant. Recuperado de https://i-d.vice.com/es/article/bjm83q/isabel-marant-caso-plagio

»Vogue (2017). La cultura colombiana deslumbra con sus mochilas. Recuperado de: http:// www.vogue.mx/moda/estilo-vogue/articulos/mochilas-colombianas-wayuu-molas-arhuacas/7647

»Wagoner, M. (23 de enero, 2015). Pat McGrath's Givenchy Surprise: Supermodels (and Major Makeup!) on the Fall 2015 Men's Runway. Recuperado de http://www.vogue.com/ article/pat-mcgrath-makeup-givenchy-fall-2015-menswear

»Wallerstein, I. (2006). Análisis de Sistemas-mundo. Una introducción. México D.F.: Siglo XXI.

"Wright, E. (10 de mayo, 2017). Colaboración Maiyet x Mola Sasa. Se unen dos grandes marcas de lujo con consciencia. Recuperado de http://www.vogue.mx/moda/estilo-vogue/ articulos/maiyet-x-mola-sasa/7309

» Ximénes, M. (16 de diciembre, 2013). Chanel se disculpa por incluir signos culturales de los nativos americanos. Recuperado de http://www.vogue.es/moda/news/articulos/chanelse-disculpa-por-la-tendencia-navajo-nativo-americana/18777

"Yan, Y. y bissell, K. (2014). The Globalization of Beauty: How is Ideal Beauty Influenced by Globally Published Fashion and Beauty Magazines?.Journal of Intercultural Communication Research, 43(3): 194-214.

"Zborowska, A. (2015). Deconstruction in contemporary fashion design: Analysis and critique. International Journal of Fashion Studies, 2(2): 185-201.

"Zozaya, P. (18 de marzo, 2010). Indio navajo. Ponchos, estampados rupestres de inspiración apache y complementos de cuero natural. Recuperado de http://www.vogue.es/moda/tendencias/articulos/indio-navajo/5203 